\title{
Ferias informales y migración laboral comercial. Apuntes para el debate del corredor fronterizo peruano-chileno
}

\section{Informal fairs and commercial labor migration. Notes for the Chilean-Peruvian border corridor debate}

Recibido el 15 de enero de 2019. Aceptado el 10 de diciembre de 2019. Publicado el 13 de diciembre de 2019.

*Autor para correspondencia: Ricardo Jiménez Palacios, correo electrónico, jpricardojp@gmail.com

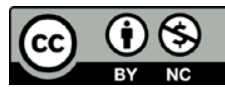

Esta obra está protegida bajo una Licencia Creative Commons Atribución-NoComercial 4.0 Internacional.

\author{
Ricardo Jiménez Palacios ${ }^{\mathrm{a}^{*}}$ (ID) https://orcid.org/0000-0001-9741-8689 \\ Priscilla Francesca Bachmann Benites ${ }^{a}$ (iD https://orcid.org/0000-0002-9779-1640 \\ Nicole Loza Delgadoa (i) https://orcid.org/0000-0003-3720-3293 \\ a Universidad Privada de Tacna, Tacna, Perú, correos electrónicos: rjimenezp@upt.pe; priscilla- \\ bachmanbenites@gmail.com; nicolozad@gmail.com
}

\section{Resumen:}

Durante los últimos cinco años ha aumentado la producción sobre la frontera peruano-chilena. No obstante, la profundización etnográfica sobre las dinámicas de este corredor permitirán ahondar sobre el carácter transfronterizo complejo del mismo, permitiéndonos debatir propuestas teóricas y metodológicas. El presente trabajo aborda las dinámicas sociales, económicas y culturales de las ferias de ropa y calzado de segundo uso en la frontera sur peruana, complementando estudios realizados en el norte chileno. Finalmente, los resultados expuestos discutirán presupuestos teóricos propuestos para el corredor fronterizo peruano-chileno. De esta manera, por medio de una metodología etnográfica desarrollada con base en las técnicas de entrevistas y observación, se busca generar evidencias de las dinámicas socio-territoriales manifiestas en la esfera pública de las referidas ferias. Finalmente, observaremos que la propia esfera pública descrita nos permite discutir las escalas territoriales de análisis del corredor fronterizo generándose indicios para considerar una escala que se extienda hasta el Altiplano peruano y boliviano.

Palabras clave: migración laboral comercial, ferias informales, frontera, Tacna, Arica.

\begin{abstract}
:
During the last five years, production has increased over the Chilean Peruvian border. However, the ethnographic deepening of the dynamics of this corridor will allow us to delve into its complex cross-border nature, allowing us to discuss theoretical and methodological proposals. This paper addresses the social, eco-
\end{abstract}

CÓMO CITAR: Jiménez, R., Bachmann, P. F. y Loza, N. (2019). Ferias informales y migración laboral comercial. Apuntes para el debate del corredor fronterizo peruano-chileno. [Informal fairs and commercial labor migration. Notes for the Chilean-Peruvian border corridor debate]. Estudios Fronterizos, 20, e037. doi:https://doi.org/10.21670/ref.1916037 
nomic and cultural dynamics of the Second-Use Clothing and Footwear Trade Shows on the southern Peruvian border, complementing studies conducted in northern Chile. Finally, the results presented will discuss theoretical assumptions proposed for the Chilean-Peruvian border corridor. In this way, by means of an ethnographic methodology developed based on interview and observation techniques, it is sought to generate evidence of the socio-territorial dynamics manifested in the public sphere of the mentioned fairs. Finally, we will observe that the public sphere itself described allows us to discuss the territorial scales of analysis of the border corridor generating indications to consider a scale that extends to the Peruvian and Bolivian Altiplano.

Keywords: commercial labor migration, informal fairs, border, Tacna, Arica.

\section{Introducción ${ }^{1}$}

Si bien la movilidad humana entre Perú y Chile ha sido una problemática abordada desde finales de la década del noventa, durante los últimos cinco años el lugar de enunciación de estos fenómenos se ha descentrado y ha puesto en debate tanto perspectivas teóricas como metodológicas de análisis (Valdebenito y Guizardi, 2015; Guizardi, Heredia, Muñoz, Riquelme y Valdebenito, 2014; Guizardi, Valdebenito, Nazal y López, 2017; Tapia, Liberona y Contreras, 2017; Liberona, Tapia y Contreras, 2017; Dammert, Bensús, Sarmiento y Prieto, 2017; Valdebenito, 2018; Dilla y Álvarez, 2018; Jiménez, 2018).

De esta manera, el lugar de enunciación de los discursos sobre la movilidad humana peruano-chilena se ha dislocado desde los centros político-académicos como Lima y Santiago, para iniciar un proceso de producción y problematización desde el norte chileno y, en menor medida, desde el sur peruano. Este nuevo lugar de enunciación tiene a la frontera peruano-chilena como un hito importante de análisis, encontrándose una interesante gama de categorías analíticas y metodológicas como la problematización de la escala territorial y los fenómenos migratorios (Tapia, 2012), la crítica al llamado "santiaguismo metodológico" (Guizardi, Nazal, Valdebenito y López, 2017), los territorios hiperfronterizos (Guizardi, Valdebenito et al., 2017), el análisis desde los territorios circulatorios (Liberona et al., 2017) o el análisis de la frontera sur peruana como nodo global (Dammert et al., 2017).

No obstante, una reflexión etnográfica sobre la frontera peruano-chilena permitirá un alcance teórico más profundo de su comportamiento, permitiéndonos advertir que las dinámicas socio-territoriales de frontera trascienden a un isomorfismo tacnoariqueño o peruano-chileno, estableciéndose circuitos, redes y nodos con el altiplano peruano y boliviano.

El análisis de uno de los fenómenos constantemente mentados en los estudios de esta frontera, como es la venta de ropa y calzado de segundo uso (Berganza y Cerna, 2011; Guizardi et al., 2014; Valdebenito y Guizardi, 2015; Tapia et al., 2017; Dammert

\footnotetext{
${ }^{1}$ El presente trabajo es producto de la investigación "Caracterización de los usuarios y comercios aledaños a las ferias ambulantes de ropa y calzado de segundo uso en la ciudad de Tacna", aprobada y financiada por la Facultad de Arquitectura y Urbanismo de la Universidad Privada de Tacna (Perú) mediante la Resolución Nro. 011-2018-UPT-FAU/CF.
} 
et al., 2017; Dilla y Álvarez, 2018), se ha agotado en el estudio de las paseras u hormigas, ${ }^{2}$ quienes transportan esta mercancía por el paso fronterizo peruano-chileno. El hecho de identificar a las paseras como cruzadores ejemplares de las fronteras (Grimson, 2004) o sujetos fronterizos del corredor tacno-ariqueño, invisibiliza un fenómeno fronterizo más amplio y escinde una mayor posibilidad de debates teóricos territoriales y fronterizos sobre el corredor peruano-chileno.

Es por esta razón que el objetivo de la presente investigación fue profundizar en las dinámicas sociales y comerciales de la feria de ropa y calzado de segundo uso con el propósito de complementar y dar cuenta de un mayor análisis de este fenómeno referido marginalmente en otras investigaciones y, a partir de ahí, considerar posibilidades teóricas y analíticas para el estudio del corredor fronterizo.

El presente artículo se divide en cuatro secciones clave: aspectos teóricos, aspectos metodológicos, resultados y conclusiones. La primera sección hemos tenido a bien subdividirla en tres partes: ¿Qué se ha dicho sobre la frontera peruano-chilena? Subtítulo que, a modo de pregunta, nos ubicará sobre la producción académica y científica sobre este corredor fronterizo. Perspectivas teóricas sobre la frontera peruano-chilena, en la cual realizamos una síntesis de los supuestos teóricos insertos en los análisis que se han hecho de esta frontera; y, Migración laboral comercial en la frontera tacno-ariqueña: El caso de las ferias de ropa y calzado de segundo uso, la cual nos contextualiza sobre este fenómeno.

La sección metodológica y de resultados van de la mano; hemos planteado una estrategia cualitativa basada en la observación etnográfica sobre la feria de ropa y calzado de segundo uso, haciendo especial énfasis en los fenómenos sociales y comerciales que circundan a estas ferias. Así, visualizamos tres actividades particulares en este fenómeno: la venta de alimentos, los servicios de transporte, y otro tipo de servicios, los cuales serán analizados bajo las tres categorías de productos o servicios ofrecidos, características de los comerciantes y disposición espacial del comercio. Finalmente, las conclusiones nos ofrecerán la síntesis de estos hechos y las posibilidades teóricas para la discusión del corredor fronterizo peruano-chileno.

\section{Marco teórico}

\section{¿Qué se ha dicho sobre la frontera peruano-chilena?}

Desde el Perú, la producción académica sobre la frontera sur tiene entre sus principales motores los estudios migratorios. Durante la década de 1990, uno de los primeros estudios sobre la migración peruana (Altamirano, s.f.) advertía que a partir de las décadas de 1950 y 1960 se tendían los primeros corredores migratorios entre el Perú y otros países latinoamericanos, principalmente Argentina y Venezuela.

Más tarde, el conflicto armado interno de 1980 multiplicó la cantidad de peruanos en el exterior, no solamente hacia Estados Unidos, Europa del Oeste o Japón, sino

\footnotetext{
2 "Se denomina comercio de hormiga, debido a que las personas que cruzan la frontera van transportando poquito a poco la mercadería. Pasan la frontera a menudo, pasando pocas cantidades cada vez" (Berganza y Cerna, 2011, p. 88).
} 
además hacia determinados países sudamericanos, entre los cuales se mantenía Argentina además de Chile (Altamirano, s.f.). Simultáneamente, la movilidad durante la década de 1990 estuvo marcada por la recesión económica y el subempleo (Altamirano, s.f.) originado por las políticas de ajuste neoliberal; mientras que, en palabras de otros autores (Alvites, 2011), el periodo de 1990 al 2007 muestra un incremento creciente y sostenido de los procesos de emigración.

Ahora, los procesos migratorios de la década de 1990 e inicios de los años 2000, conllevaron a la consolidación de estudio migratorios especificados en determinados asuntos como las remesas (Altamirano, 2009) o el sostenimiento de las relaciones familiares a la distancia (Alvites, 2011), siendo que la movilidad de peruanos hacia Chile fue tornándose en un ámbito de estudio por explorar.

Sin embargo, uno de los materiales que cobraría mayor importancia sería la investigación llevada a cabo por Berganza y Cerna (2011) sobre la movilidad humana entre las ciudades de Tacna (Perú), Arica e Iquique (Chile), profundizando en las dinámicas de la movilidad fronteriza y descentrando las reflexiones sobre la emigración peruana desde otras ciudades del país, más allá de la metrópolis limeña. Además, en el año 2017 se publicó una investigación sobre fronteras, informalidad y economías ilegales en el Perú (Dammert et al., 2017), donde se da cuenta de la importancia de las ciudades fronterizas para articular circuitos de mercados informales e ilegales en el marco de un sistema global.

Respecto de los estudios desde la academia chilena, es importante anotar que “desde los años noventa, la preocupación por la migración en Chile tomó dimensiones importantes, acaparando discursos comunicacionales y políticos, e inspirando una ingente producción académica" (Guizardi, Nazal et al., 2017, p. 29). No obstante, como señalan más adelante Guizardi, Nazal y colaboradores (2017), la producción académica chilena a partir de los años 2000 presentará una diversidad de estudios socio-antropológicos que dan cuenta del fenómeno migratorio en Chile.

Si bien la presente mención es para dar cuenta del origen de la preocupación por estudios sociales en torno a las relaciones peruano-chilenas, no está de más advertir que los estudios migratorios chilenos de la primera década del 2000 padecerán de determinados sesgos como el supuesto de que Chile se consolida en un destino migratorio latinoamericano prioritario a fines de los años noventa hasta la actualidad, o como el supuesto de que la migración es un fenómeno predominantemente santiaguino.

Posterior a estos primeros estudios migratorios peruano-chilenos, es importante considerar investigaciones que darán cuenta del fenómeno a partir del norte de Chile; entre estas se encuentran las de Valdebenito y Guizardi (2015) quienes desarrollan una etnografía de las migrantes peruanas en el norte de Chile; Guizardi et al. (2014) ofrecen un estudio etnográfico visual sobre las apropiaciones espaciales de migrantes peruanos y bolivianos en el Terminal Internacional de Arica y sus inmediaciones; Guizardi, Nazal y colaboradores (2017), ofrecen una perspectiva metodológica crítica sobre los estudios migratorios en Chile; Tapia et al. (2017) hacen un importante aporte sobre la problematización de la movilidad humana en el norte chileno y sur peruano 
desde una perspectiva del territorio circulatorio; ${ }^{3}$ Liberona et al. (2017) ofrecen una investigación sobre la movilidad del norte chileno hacia el sur peruano por las ofertas de servicio de salud; Valdebenito (2018) nos comparte perspectivas críticas en torno a los conceptos de complejos urbanos transfronterizos y regiones transfronterizas para el análisis de la realidad tacno-ariqueña; y finalmente, Dilla y Álvarez (2018) aportan un análisis de los fenómenos migratorios entre el norte chileno y el sur peruano desde la perspectiva teórica de los complejos urbanos transfronterizos. ${ }^{4}$

Recapitulando observaremos que la producción académica en torno al fenómeno peruano-chileno va a tener su origen en un fenómeno, probablemente tergiversado (Guizardi, Nazal et al., 2017), sobre el desbordante proceso migratorio peruano en territorio chileno, el cual recibirá la atención de la academia de ambos países. No obstante, a partir de la segunda década del siglo xxi, el problema peruano-chileno empieza a descentrarse y ubica sus problemas de investigación y sus lugares de enunciación en los territorios fronterizos mismos, siempre con mayor énfasis en la academia chilena sobre la peruana.

Sin embargo, otro hecho importante para las relaciones peruano-chilenas permitirá consolidar distintas líneas de investigación. En este transcurso, el año 2014, el Fallo de la Corte Internacional de Justicia de La Haya en referencia al diferendo marítimo entre Perú y Chile (Ministerio de Relaciones Exteriores de Perú [MRE], 2015), consolidó una línea trabajada en años anteriores sobre fronteras desde una perspectiva metodológica en clave nacional e institucional, con especial énfasis en estudios de historia binacional (Cavieres, 2006; Cavieres y Aljovín de Losada, 2005; Parodi y González, 2014; Cavieres, 2015), en los estudios de educación e interculturalidad (Bustos, 2017; Pizarro y Bustos, 2015), o en estudios de relaciones internacionales (Panfichi y Venero, 2017).

Finalmente, preguntarnos qué se ha dicho sobre la frontera peruano-chilena nos advierte una serie de problemas como el centralismo en la concepción de la problemática fronteriza, desde las bases teóricas y metodológicas para su análisis. Por otro lado, se observa que el problema de la frontera peruano-chilena se encuentra íntimamente relacionado con el fenómeno de la movilidad, sin advertirse aún otras problemáticas como las economías del delito, las políticas comerciales, los problemas hídricos y la gobernanza territorial, entre otros tópicos.

\footnotetext{
${ }^{3}$ El término territorio circulatorio, desarrollado por Alain Tarrius, refiere a "la socialización de espacios que sirven de soporte a las prácticas de movilidad" (citado por Tapia et al., 2017, p. 119), permitiéndonos dos acepciones críticas a la circulación y el territorio: la primera de ellas, la negación de la premisa de la sedentarización como un elemento fundamental para la territorialización; y la segunda, la que nos refiere que una concepción que otorgue sentido social al movimiento espacial requiere la ruptura de conceptos como circulación o flujos.

La adopción del territorio circulatorio para el análisis de la frontera chileno-peruana permite problematizar conceptos de movilidad que, en análisis previos (Altamirano, 2009; Alvites, 2011), priorizarían las dinámicas territoriales intermetropolitanas o el cambio de residencia como elemento esencial del fenómeno migratorio.

Ahora, si bien el abordaje cuantitativo de la investigación permite generar interesantes evidencias sobre este territorio fronterizo, cabría preguntarnos si el propio concepto de territorio circulatorio es capaz de interpelar nuestro abordaje hacia categorías territoriales más amplias que desborden lo propiamente tacno-ariqueño o lo chileno-peruano, considerándose las prácticas socio-espaciales del altiplano peruano y boliviano en este territorio.

${ }^{4}$ Como indica Haroldo Dilla (2015), los complejos urbanos transfronterizos (CUT) sugieren un concepto de complejidad lo suficientemente amplio para abordar diversas interacciones y conformaciones sistémicas socio-territoriales, mientras que el carácter transfronterizo hace referencia a la relación de actores de comunidades en interacción. De ahí que el término cuT sea lo suficientemente flexible para abordar diversas situaciones específicas.
} 
En suma, los estudios migratorios peruano-chilenos nos permiten señalar una academia recientemente descentralizada que empieza a advertir sobre determinados fenómenos y corredores fronterizos, lo cual debe llevarnos a indagar en las bases teórico-territoriales que se asumen al momento de interpretar la realidad fronteriza peruano-chilena.

\section{Perspectivas teóricas sobre la frontera peruano-chilena}

Ahora bien, las indagaciones sobre la frontera peruano-chilena no son ajenas a un debate intrínseco de teorías territoriales. Tomando en cuenta la producción sobre esta frontera desarrollada durante la segunda mitad del siglo xxI, derivaremos algunos supuestos territoriales, lo cual implica dos aspectos puntuales.

El primero de ellos, dejar de lado aquellos estudios migratorios construidos desde una perspectiva nacional metodológica, lo cual implica el empleo de la escala nacional para cualquier tipo de análisis social y político, lo que además trae consigo concebir a la sociedad nacional como unidad de análisis (Massó, 2013). En este grupo incluimos a los primeros estudios peruanos sobre emigración (Altamirano, s.f.; Alvites, 2011) y, en cuanto a la academia chilena, a los trabajos referidos por Guizardi, Nazal y colaboradores (2017). Esta división la apuntamos en el sentido de diferenciar la primera fase de la producción sobre las relaciones peruano-chilenas, de la producción posterior donde las investigaciones se ubican en regiones concretas como el sur peruano (Berganza y Cerna, 2011; Pastor, 2017; Ponce, 2017; Ponce, 2018); las fronteras peruanas (Dammert et al., 2017; Jiménez, 2018; Jiménez, 2019); o el norte chileno (Valdebenito y Guizardi, 2015; Guizardi et al., 2014; Guizardi, Valdebenito, et al., 2017; Tapia et al., 2017; Liberona et al., 2017; Valdebenito, 2018; Dilla y Álvarez, 2018).

La revisión crítica de las migraciones desde Perú hacia Chile conllevarán a reconsiderar perspectivas teóricas y metodológicas desde la problematización de la escala territorial de análisis (Tapia, 2012), la adopción de la propuesta del territorio circulatorio y la determinación del mismo por medio de las prácticas de movilidad fronteriza (Tapia et al., 2017; Liberona et al., 2017), así como la diferenciación de las trayectorias migratorias a partir de una perspectiva crítica del nacionalismo o santiaguismo metodológico (Guizardi, Nazal et al., 2017), reconstruyendo territorios a partir del análisis etnográfico de las prácticas fronterizas (Guizardi et al., 2014); Valdebenito y Guizardi, 2015) o estableciendo nuevas categorías analíticas como los espacios hiperfronterizos $^{5}$ (Guizardi, Valdebenito et al., 2017) o la construcción de una escala propia de urbanización fronteriza tacno-ariqueña (Valdebenito, 2018).

\footnotetext{
${ }^{5}$ El espacio hiperfronterizo es una construcción teórica que se deriva a partir del análisis etnográfico del Terminal Internacional de Arica y sus inmediaciones. Por medio del análisis etnográfico se determina que el propio Terminal se constituye en un espacio fronterizo dentro del propio espacio fronterizo tacno-ariqueño. La presencia de migrantes en el Terminal y alrededores no se desarrolla como un enclave étnico, cerrado en sí mismo y separado del propio territorio fronterizo. Es más bien la propia dinámica migrante la que se interrelaciona sincrónicamente con el propio territorio fronterizo.
} 
Asimismo, en los estudios sobre el sur peruano y su relación con el norte chileno es importante tomar en cuenta la interrelación entre Tacna y Puno, ${ }^{6}$ ya sea en la construcción de las periferias de la ciudad (Ponce, 2018), las inserciones laborales y la ocupación de la vivienda (Ponce, 2017), la consideración de aspectos identitarios y los conflictos por la ocupación del espacio urbano (Pastor, 2017); así como la interrelación con el norte de Chile (Berganza y Cerna, 2011), el rol territorial de la frontera sur peruana como nodo global (Dammert et al., 2017), o el comercio transfronterizo y la movilidad laboral comercial (Jiménez, 2018; Jiménez, 2019).

La producción peruana que, a diferencia de la producción chilena, se desarrolla desde libros y tesis, presenta diversas interpretaciones territoriales. Así, podemos considerar a quienes estudian el desarrollo urbano del sur peruano bajo un estudio etnográfico (Pastor, 2017; Ponce, 2017; Ponce, 2018), reconstruyendo las trayectorias territoriales con base en técnicas de entrevistas a profundidad, revisión documental y observación.

En lo que respecta a los abordajes específicamente fronterizos, el trabajo de Dammert y colaboradores (2017) considera a la territorialidad bajo una lógica zonal, entendida como el continuo espacial, y una lógica reticular, producto del proceso de globalización. De esta manera, las ciudades de frontera han de ser analizadas considerándose las diversas manifestaciones de estas lógicas territoriales y sus diversos efectos escalares. En cuanto al trabajo de Berganza y Cerna (2011), se considera una polisemia de la frontera en tanto límite natural, político y cultural, en donde las relaciones fronterizas están pautadas por las prácticas locales, las convenciones sociales y la normativa estatal; esta percepción permite diferenciar las trayectorias migratorias del sur peruano y el norte chileno frente a las trayectorias migratorias desde el centro y norte peruano hacia las principales ciudades de Chile. Finalmente, Jiménez (2018) considera un análisis de la construcción social del territorio a una escala local fronteriza, que entra en conflicto con las determinaciones jurídicas de la escala global.

En segundo lugar, referirnos a las perspectivas teórico-territoriales que han acompañado a las reflexiones sobre la frontera peruano-chilena debe llevarnos a hacer un breve repaso por la reflexión teórica en torno a las fronteras como categoría analítica. Sin embargo, en aras de la síntesis, nos referiremos a las reflexiones territoriales que han acompañado a los planteamientos fronterizos sudamericanos; en cierta medida, las reflexiones fronterizas sudamericanas son deudoras de las reflexiones de la frontera México-Estados Unidos.

A partir de la década de 1980 entra en vigor una serie de teorías sobre la frontera México-Estados Unidos que pasarán a interpretarla como región transfronteriza (Bustamante, 1989) o metrópolis transfronteriza (Herzog, 1990); no obstante, Tito Alegría (2009) desarrollará una revisión crítica de ambos conceptos considerando que el par Tijuana-San Diego no puede ser considerado como un sistema armónico o como una metrópoli transfronteriza en tanto que "no estamos frente a una unidad metropolitana transfronteriza sino frente a dos ciudades vecinas que tienen diferentes formas urbanas, diferentes modos de generar esa forma urbana y una tendencia a la divergencia estructural" (Alegría, 2009, p. 353).

\footnotetext{
${ }^{6}$ Departamento peruano fronterizo con Bolivia.
} 
La tesis de Tito Alegría (2009) es discutida por Haroldo Dilla (2008) sobre la teoría de los complejos urbanos transfronterizos, los cuales se entienden como sistemas complejos que "funcionan en medio de contradicciones debido a la prevalencia de asimetrías y diferentes modalidades de intercambio desigual, lo cual puede generar fuertes tensiones políticas y culturales" (Dilla, 2008, p. 170), siendo que la tesis de los complejos urbanos transfronterizos será utilizada para interpretar la frontera tacnoariqueña (Dilla y Álvarez, 2018).

Finalmente, es importante observar que la propuesta de los complejos urbanos transfronterizos (Dilla, 2008; Dilla y Álvarez, 2018), así como la crítica a las metrópolis transfronterizas (Alegría, 2009) se enmarcan en un debate de la "expresión de lo transfronterizo en las ciudades, metrópolis o conglomerados urbanos situados en las fronteras" (Tapia, 2017), rescatando la importancia de las prácticas fronterizas producto de las asimetrías - como núcleo de la transfrontericidad territorial en el caso de Tacna (Perú) y Arica (Chile).

Ahora bien, aunque el estudio del espacio tacno-ariqueño ha cobrado importancia a partir del análisis crítico de las migraciones entre Perú y Chile, es importante generar mayores evidencias investigativas que nos permitan asentir enfoques teóricos y metodológicos propuestos en los últimos años. Así, por ejemplo, la complejidad manifiesta en la propuesta del territorio circulatorio (Tapia et al., 2017), los complejos urbanos transfronterizos (Dilla, 2015) o los espacios hiperfronterizos (Guizardi, Valdebenito et al., 2017), ¿nos llevarán, indefectiblemente, a desbordar la categoría territorial de análisis tacno-ariqueña o chileno-peruana, para repensar categorías socio-espaciales más amplias? Cabría preguntarnos: ¿estamos únicamente ante una relación tacno-ariqueña o chileno-peruana? ¿O una relación necesariamente interurbana? ¿Puede insertarse al altiplano en esta relación fronteriza?

Para ello, a continuación desarrollaremos un análisis etnográfico de las prácticas comerciales informales en la ciudad de Tacna a partir de los mercados de contrabando de bienes traídos desde el norte de Chile, lo cual nos permitirá un acercamiento mayor a las relaciones transfronterizas.

\section{Migración laboral comercial en la frontera tacno-ariqueña: El caso de las ferias de ropa y calzado de segundo uso}

Tapia y colaboradoras (2017) advierten una serie de movilidades y prácticas socioespaciales fronterizas entre las ciudades de Tacna (Perú) y Arica (Chile), considerando a la movilidad como una práctica socio-espacial que supone una circulación fronteriza frecuente sin cambio de residencia. Además, estas prácticas socio-espaciales fronterizas entre ambas ciudades son categorizadas como actividades productivas y reproductivas.

La movilidad laboral comercial (Tapia et al., 2017) es considerada una práctica productiva, en tanto estrategia para lograr beneficios económicos o medios materiales de subsistencia. Junto a esta práctica se encuentra la movilidad laboral remunerada, la movilidad laboral independiente, la movilidad laboral in between y la movilidad laboral de temporada. En suma, la movilidad laboral comercial consiste en "comerciantes que cruzan la frontera para comprar productos en un lado para venderlos luego en el otro" (Tapia et al., 2017, p. 132). 
En cuanto a la feria de ropa y calzado de segundo uso, tuvo su origen en el intercambio comercial fronterizo beneficiado por el Régimen Especial de Frontera del Tratado de Lima de 1929, ${ }^{7}$ el cual permitía el libre tránsito del comercio de Arica (Chile) hacia Tacna (Perú), beneficiándose del puerto libre, la estación peruana de ferrocarril en Arica y la agencia de aduanas.

Entre las diversas actividades beneficiadas por el libre comercio fronterizo del Régimen Especial, una actividad tan cotidiana y local como la de los ropavejeros adquirirá un matiz transfronterizo. Según relato de los propios dirigentes de las ferias de ropa y calzado de segundo uso, hacia finales de la década de 1980 e inicios de la década de 1990 un nutrido sector de la población peruana residente en Tacna intercambiaba enseres de plástico tales como bateas, jarras y baldes, a cambio de diversos productos en Arica, como ropa y calzado usado, juguetes, herramientas usadas, mallas, sogas, chatarra, etcétera. ${ }^{9}$

Esta situación cobra un matiz particular cuando empieza a llegar ropa americana de segundo uso a los puertos del norte chileno:

Porque nosotros mismos pedíamos. Hablábamos de que ropa americana estaba ingresando y decíamos: tráiganos pues ropa americana, porque nosotros no podíamos pasar hasta Iquique porque no teníamos carnet, así que le decíamos tráenos, tráenos a los caseros (comerciante peruano, 60 años, citado por Jiménez, 2018).

Uno de los principales factores relacionados con la llegada de ropa americana de segundo uso al norte chileno es la creación de la Zona Franca de Iquique a finales de la década de 1970. La dinámica fronteriza originada por el fortalecimiento de un nodo comercial en el puerto de Iquique, implicó la creación de tiendas locales en Arica, tales como María Eugenia u Holguín, las cuales abastecerán a los comerciantes de ropa y calzado de segundo uso en el sur peruano.

No obstante, las reformas de ajuste neoliberal de la década de 1990 tendrán su efecto sobre las dinámicas comerciales fronterizas en el caso peruano, específicamente en torno a la creación de los Centros de Exportación, Transformación, Industria, Comercialización y Servicios (CETICOS). La creación de los CETicos para las zonas sur del Perú transformarán las dinámicas de comercio fronterizo de un intercambio transfronterizo a escala local a un intercambio transfronterizo a escala global. Así, el Régimen Comercial de los CETicos se posicionará de forma paralela con el Régimen Especial de Frontera utilizado por los comerciantes de ropa y calzado usados.

\footnotetext{
${ }^{7}$ Para entender el Tratado de Lima de 1929, es importante considerar el Tratado de Ancón de 1883. El Tratado de Ancón puso fin al conflicto armado entre Perú y Chile iniciado en 1879; entre otras cosas, dicho tratado ponía fin al conflicto cediendo a Chile las provincias peruanas de Tacna, Arica y Tarapacá, las dos primeras por diez años y la segunda de manera perpetua. No fue sino 50 años más tarde, con la firma del Tratado de Lima, que los gobiernos de Perú y Chile acordarán que la provincia de Tacna retorne al Perú y la provincia de Arica permanezca en Chile.

8 "Persona que vende, con tienda o sin ella, ropas y vestidos viejos, y baratijas usadas" (Real Academia Española, 2005, p. 1350).

${ }^{9}$ Esta información se corrobora con lo que Fernando Graña (2001) llama cambio casera: aquel grupo de comerciantes peruanas que recorre, de puerta en puerta, la ciudad de Arica recolectando productos de plástico a cambio de ropa y zapatos usados. Es importante anotar que Sonia Zarzuri (citada por Graña, 2001) evidenciaba que en la década de 1960 ya se establecía una figura similar pero dedicada al rubro de productos agrícolas.
} 
Hasta cierto punto, la ropa y calzado usados se convierte hoy en una mercadería que transita diversos corredores a escala global, desde su origen en la producción asiática y su uso en el norte global (Pérez, 2013), hasta diversos corredores portuarios que se anclan en el puerto sudamericano de Iquique, para posteriormente transitar por diversos corredores fronterizos como Tacna-Arica, Perú-Chile (Jiménez, 2018) o Corumbá-Puerto Quijarro en la frontera de Brasil y Bolivia (Hernández y Loureiro, 2017), por mencionar solo dos casos de estudio de este fenómeno.

Con base en los antecedentes revisados en secciones anteriores, damos cuenta de que el comercio de ropa y calzado usados se ha advertido en más de un estudio, aunque no de una manera sistemática. Así, se ha hecho referencia principalmente al trabajo de las paseras en el Terminal Internacional de Buses en la ciudad de Arica (Guizardi et al., 2014; Valdebenito y Guizardi, 2015), al trabajo de las comisionistas en el tránsito de mercancías por la frontera (Dilla y Álvarez, 2018), al énfasis en la movilidad laboral comercial y el carácter transfronterizo del comercio informal (Berganza y Cerna, 2011; Tapia et al., 2017; Dammert et al., 2017) y al desarrollo comercial urbano en la ciudad de Tacna (Ponce, 2017; Pastor, 2017).

En suma, se ha dado cuenta de diversos momentos del comercio informal transfronterizo o de la movilidad laboral comercial, pero no desde un abordaje sistemático e integral. En el tránsito de la mercancía desde el puerto de Iquique hasta el corredor tacno-ariqueño se desarrolla, en la práctica, una importante estructura laboral informal y organizativa que involucra a una diversidad de actores entre comerciantes, comisionistas y hormigas o paseras. Siendo que los comerciantes son quienes disponen del capital para la compra y venta de los productos y quienes, a su vez, contratan a comisionistas quienes se encargan de organizar el cruce de la mercadería por el paso fronterizo, para lo cual subcontratan a paseros u hormigas que, finalmente, por medio de sus cuerpo u otras modalidades, traen consigo la mercadería para llevarla a la ciudad de venta, en este caso Tacna (Perú) (Figura 1).

Figura 1: Esquema de la organización del comercio informal tacno-ariqueño

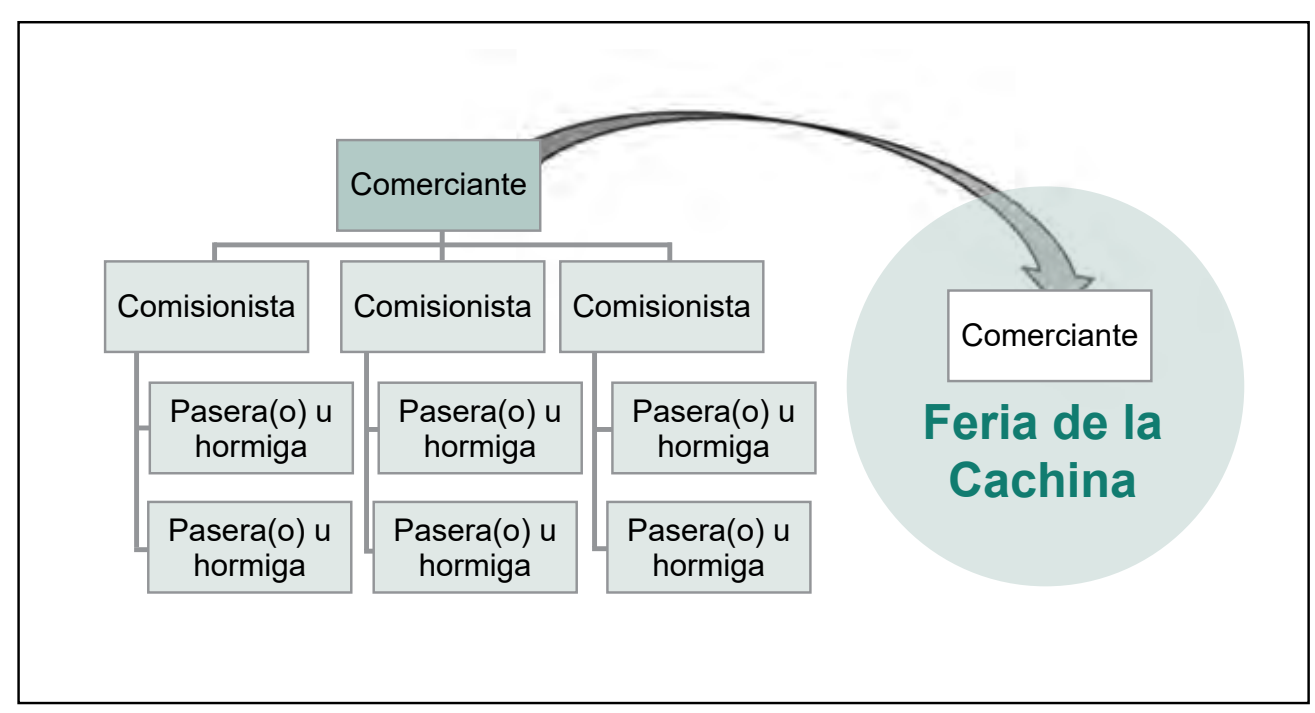

Fuente: Jiménez (2018). 
A su vez, si bien hemos profundizado sobre las características socio-económicas de la feria de ropa y calzado de segundo uso en otros materiales (Jiménez, 2018; Jiménez, 2019), en esta oportunidad debemos advertir que esta concentra una serie de negocios informales satélites así como dinámicas comerciales y de socialización que permiten dilucidar la concreción de corredores económicos transfronterizos no solamente entre Tacna (Perú) y Arica (Chile), sino además con zonas del altiplano en Perú y Bolivia. El presente estudio profundizará estas dinámicas comerciales y de socialización en las propias ferias, dando cuenta de la extensión de los corredores fronterizos más allá de un mentado isomorfismo tacno-ariqueño. ${ }^{10}$

\section{Aspectos metodológicos}

Dado que el objetivo del presente artículo es profundizar en las dinámicas comerciales y de socialización en torno a las ferias de ropa y calzado de segundo uso, hemos tenido a bien categorizar la complejidad y diversidad de actividades que caracterizan al comercio informal a este respecto. De esta manera, hemos considerado tres grandes grupos de actividades:

a) Venta ambulante de alimentos, entre desayunos, meriendas, comidas y bebidas al paso.

b) Servicios de transporte, de personas y carga de mercaderías.

c) Otro tipo de servicios, entre telefonía móvil, microfinancieras, servicios de salud y cuidado, entre otros (Figura 2).

Figura 2: Actividades económicas insertas en las ferias de ropa y calzado de segundo uso

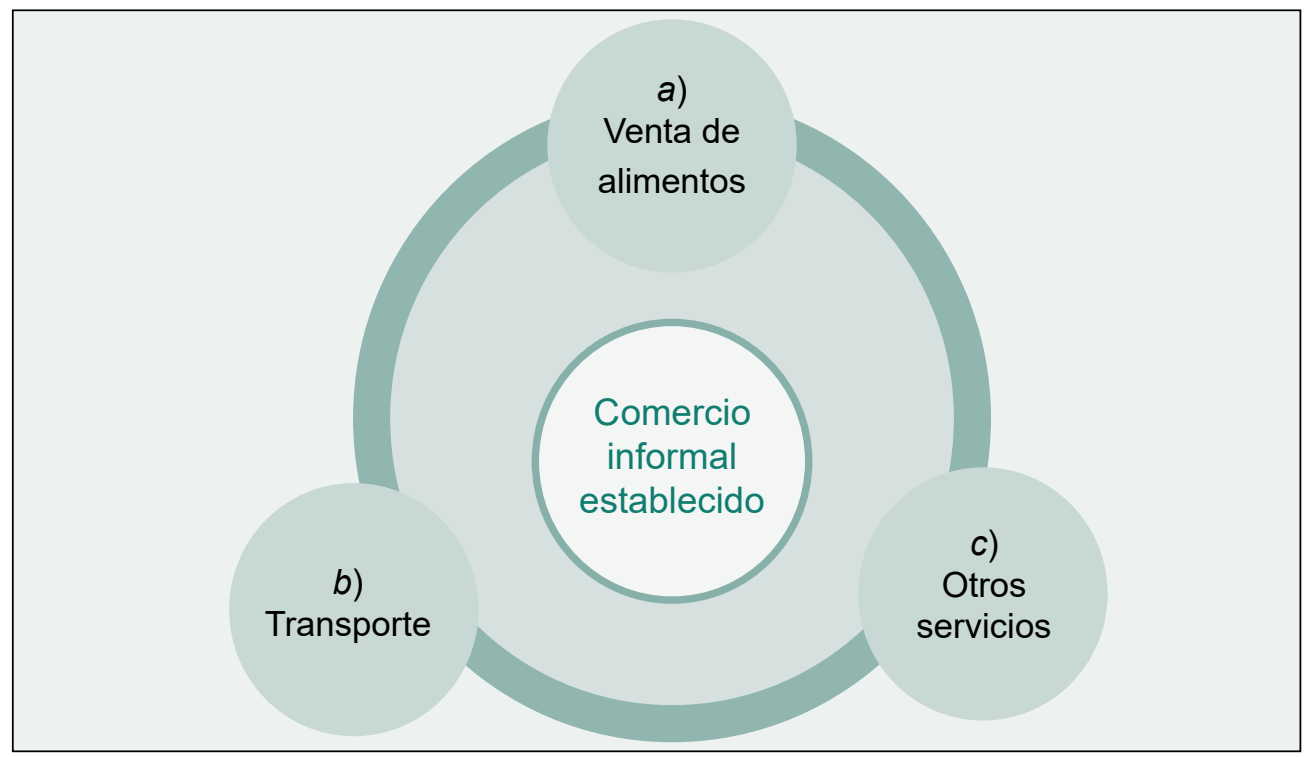

Fuente: Elaboración propia.

\footnotetext{
${ }^{10}$ Como señala Valdebenito $(2018$, p. 306), se requiere "construir una escala o un enfoque geográfico mucho más amplio del que hasta ahora se ha utilizado para comprender la frontera tacno-ariqueña. Una escala o enfoque geográfico que logre superar el isomorfismo espacial con el que hasta ahora se ha estudiado" esta frontera.
} 
Para el estudio de las ferias y sus dinámicas comerciales y de socialización, hemos utilizado la técnica de la observación etnográfica, la cual comprendemos como una herramienta que va más allá de una simple contemplación y busca adentrarnos profundamente en las situaciones de estudio, manteniendo un rol activo, una reflexión permanente y una consolidación de lazos de confianza con el espacio y los actores involucrados, atendiendo los diversos detalles e interacciones que el fenómeno manifiesta (Hernández, Fernández y Baptista, 2010, p. 411).

Asimismo, los apuntes de campo fueron sistematizados con base en tres categorías: los productos comerciados, las características comerciales, y la disposición espacial de los negocios informales; categorías sobre las cuales fueron analizados los tres grupos de comercio antes mencionados en los alrededores de las ferias de ropa y calzado de segundo uso.

\section{Resultados}

Para la exposición de resultados dividiremos esta en los tres grupos de comercios aledaños a las ferias de ropa y calzado de segundo uso, cada una de estos se subdividirá en las categorías de productos comerciados, las características de los comerciantes e inserción espacial de los negocios informales. Finalmente, haremos una breve síntesis previa a las conclusiones.

\section{La venta de alimentos}

La venta de alimentos en las ferias de ropa y calzado de segundo uso renueva su oferta en relación a la hora del día. La diversidad de productos comerciados, así como las particularidades de las y los comerciantes nos mostrarán una serie de características socio-culturales cuya interpretación nos permite reconsiderar categorías de análisis territorial para el corredor fronterizo peruano-chileno.

La jornada se inicia con la venta de desayunos, comidas de media mañana, almuerzos y comidas de media tarde. La venta de desayunos puede variar desde extractos de frutas y verduras hasta bebidas calientes de $a p i,{ }^{11}$ maca, avena, soja, entre otras bebidas que son acompañadas de empanadas y sopaipillas. ${ }^{12}$ Asimismo, dentro de la oferta de alimentos se brindan almuerzos, entre los que se cuenta con sopa de chakepa, chairito, thimpo de trucha, mazamorra de cal, queso frito, chicharrón de alpaca, sopa de chuño, así como picante a la tacneña, picante de mariscos, ceviche y arroz con pollo. Como comenta un dirigente de los comerciantes:

Los que traen soja y quaquer igual, en la mañana vienen con su bolsita de soja, compran, lo dejan, ofrecen, compran. Temprano también venden extracto

\footnotetext{
${ }^{11}$ Término proveniente del quechua, el cual significa granos de maíz. Vocablo masculino utilizado en Perú, Bolivia y norte de Argentina, definido como "alimento que se prepara con maíz morado triturado, sazonado con diversos ingredientes" (Real Academia Española, 2010). Asimismo, Carmen Pérez (2011) argumenta que el api es típico de las ciudades bolivianas de La Paz, Oruro, Cochabamba y Potosí.

12 Vocablo femenino utilizado en Perú, Bolivia, Chile y norte de Argentina, definido como "sopaipa, masa que, bien batida, frita y enmelada, forma una especie de hojuela gruesa" (Real Academia Española, 2010).
} 
de zanahoria, igual, tempranito vienen. Acá todos hace negocio, todos compramos, nadie se va sin vender nada, siempre venden algo para sostener su hogar (dirigente de comerciantes citado por Jiménez, 2018).

Posterior a la oferta de desayunos, los cuales van desde las primeras horas de la mañana hasta las $10 \mathrm{u} 11$, ofrecida tanto a los comerciantes como a los usuarios y clientes de las ferias de ropa usada, se procede a la venta de alimentos de media mañana entre lo que puede ofrecerse gelatinas, helados, dulces y huevos de codorniz, entre otros alimentos. Como refieren los dirigentes comerciantes, las horas de reparto de la comida de media mañana sirven, a su vez, para cobrar los alimentos ofrecidos a primeras horas del día: los desayunos:

Otros negocios, vienen heladeros, huevitos de codorniz, frutas también, esas personas que están pasando (personas con discapacidad), venden sus chocolates, pilas, papel higiénico, venta de discos, música. Y las señoras que dejan en la mañana el desayuno, las madres gestantes, están gestando, pero también están cobrando, cobran después de haber dejado el desayuno (entrevista a dirigente comerciante, citado por Jiménez, 2018).

Figura 3: Mujer comerciante de frutas

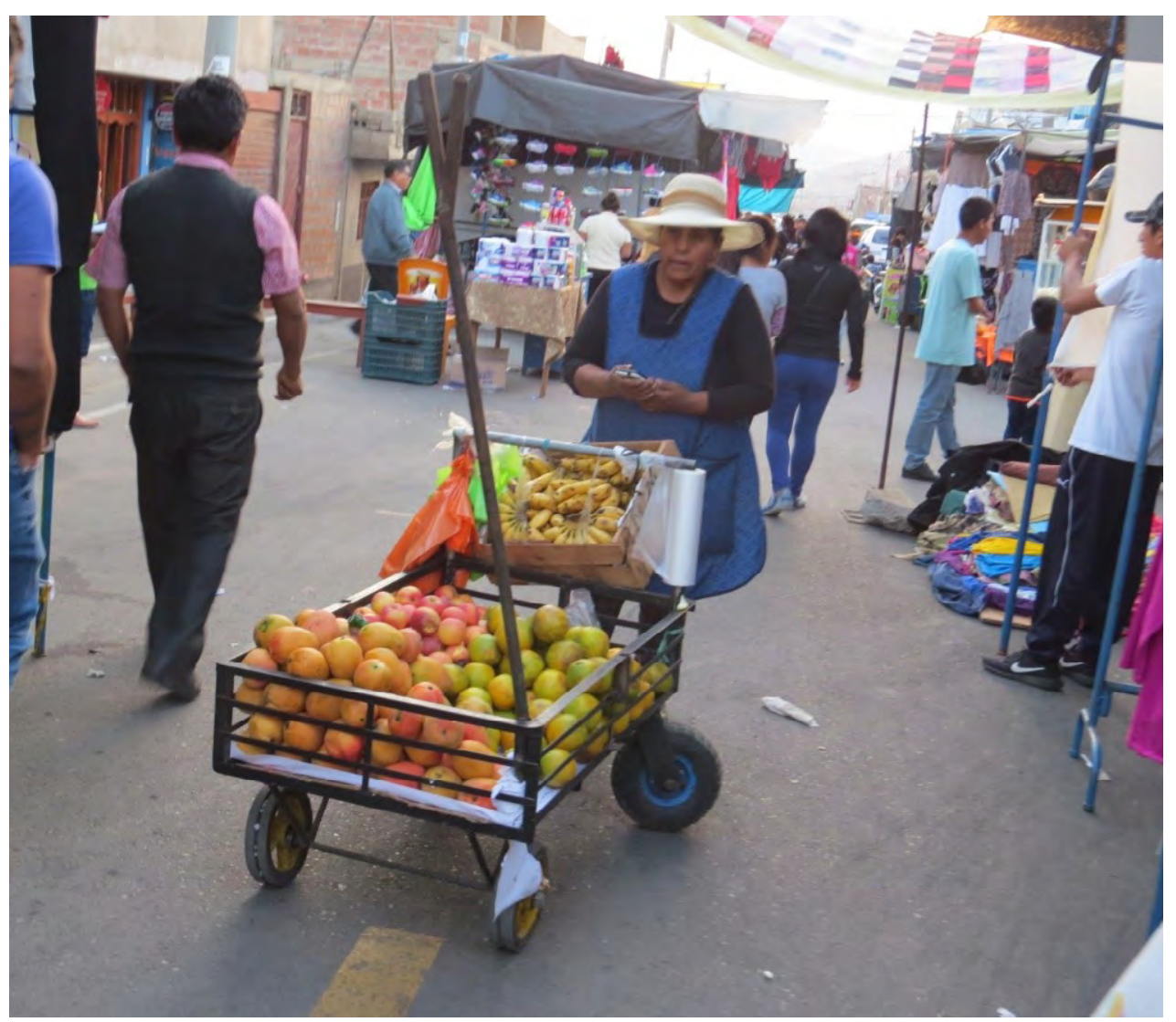

Fuente: Archivo personal. 
En las primeras horas de la tarde, inmediatamente después del mediodía, se inicia la venta de almuerzos los cuales pueden ser de diversa oferta, encontrándose sopa de chakepa, chairito, thimpo de trucha, mazamorra de cal, queso frito y chicharrón de alpaca. Estos alimentos son ofrecidos tanto a los comerciantes de puesto en puesto como a los usuarios de la feria, quienes pueden encontrar una oferta de productos provenientes, principalmente, del altiplano sudamericano (Figura 3, Figura 4 y Figura 5).

Figura 4: Oferta de alimentos

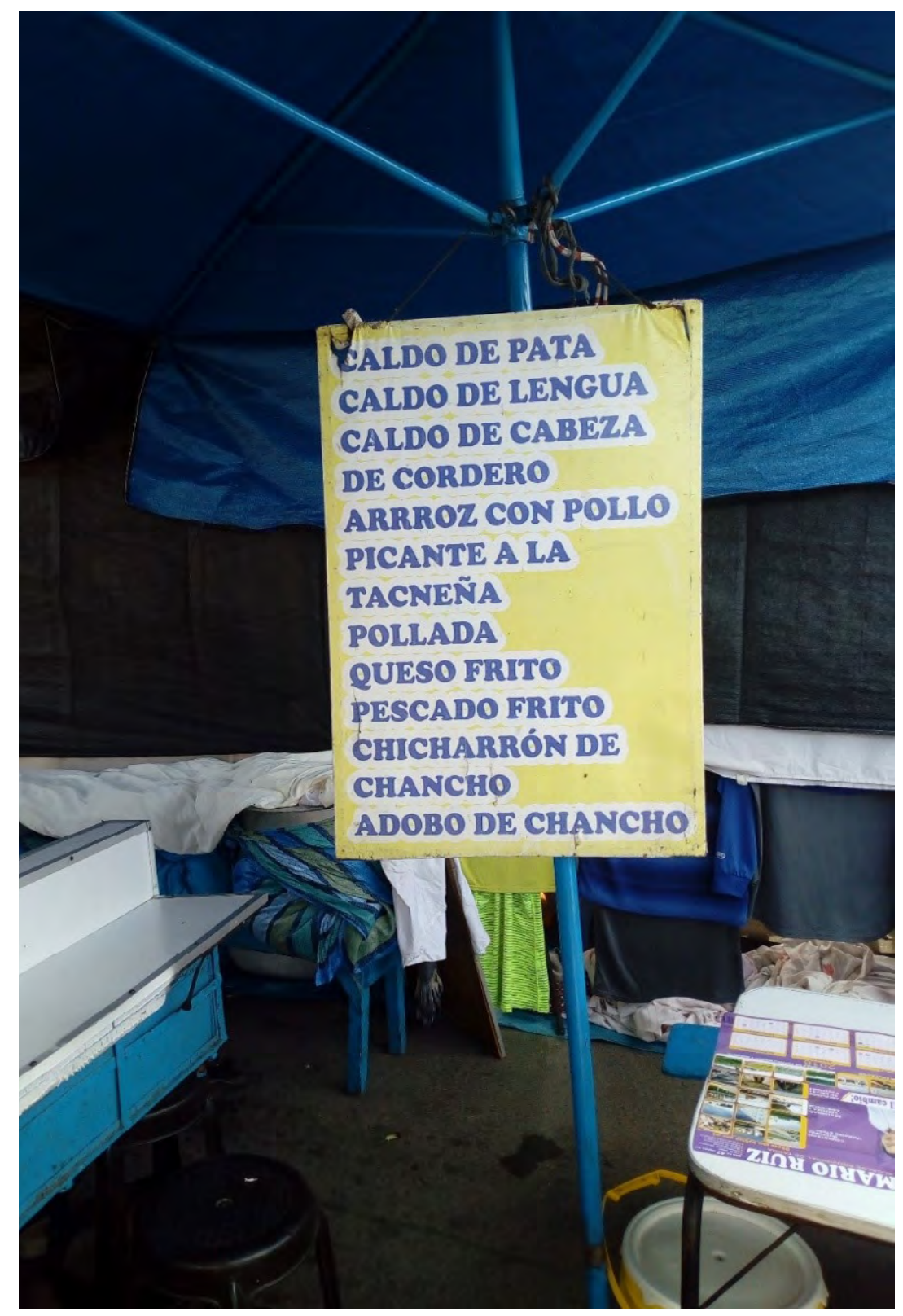

Fuente: Archivo personal. 
Figura 5: Oferta de alimentos: chicharrón de alpaca y thimpu de trucha

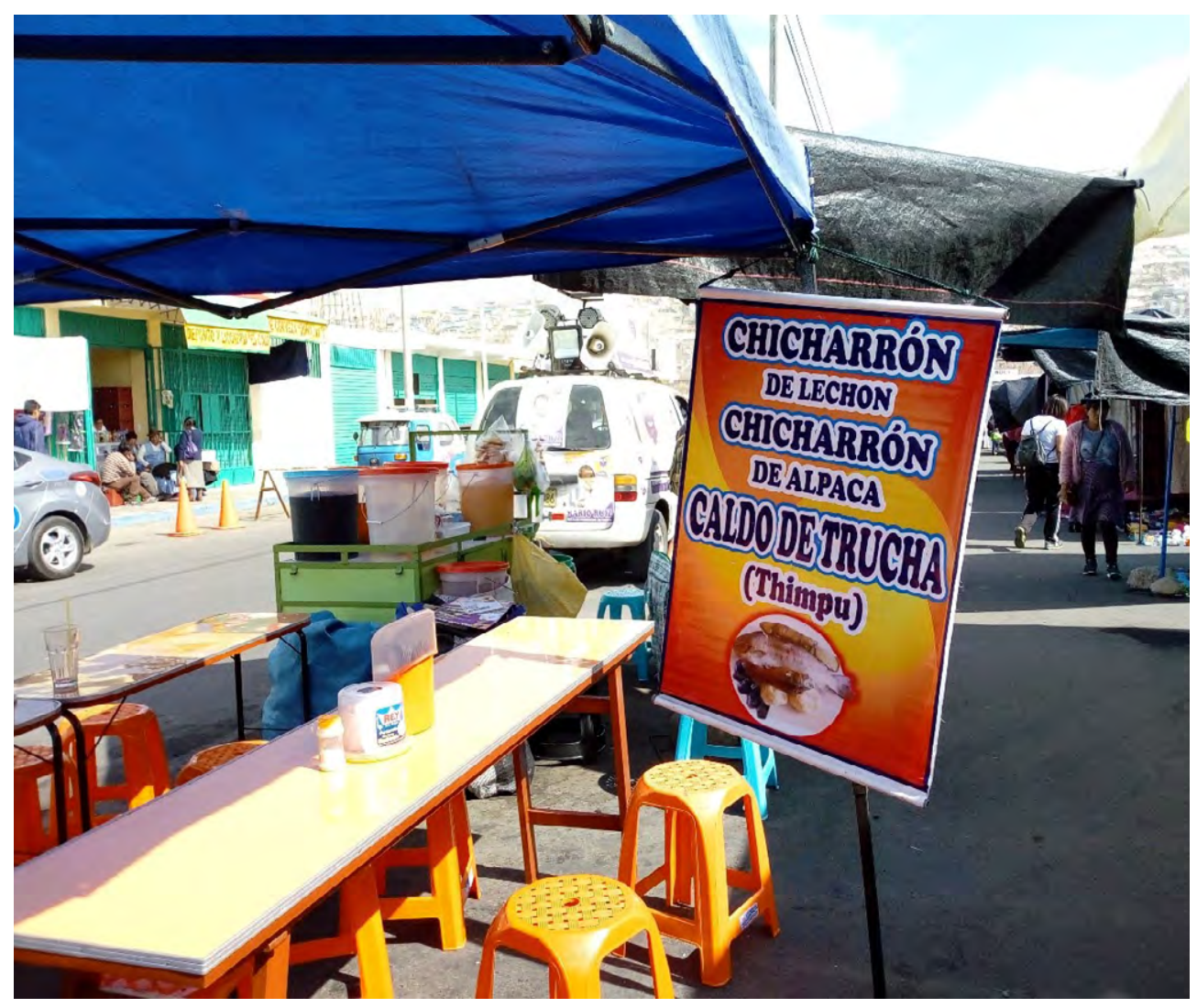

Fuente: Archivo personal.

De esta manera, los productos comerciados por los vendedores de alimentos nos llevan a replantear la constitución del corredor fronterizo peruano chileno. Si limitamos el corredor fronterizo a la relación tacno-ariqueña, ¿cómo explicaríamos la presencia cultural del altiplano propia del corredor fronterizo peruano-boliviano en una actividad comercial reconocida como propiamente fronteriza por la academia?

Esta misma duda la encontramos en las características de los comerciantes de venta de comida. Es importante recordar que la venta de ropa y calzado de segundo uso, no es una simple actividad de paso de mercancías, supone dinámicas y anclajes territoriales en cada uno de sus diversos procesos: en la compra de la ropa en Iquique o Arica (Chile), la organización de la misma en el Terminal Internacional de Arica (Chile), el traslado clandestino de la ropa por los puestos fronterizos de Perú y Chile, el traslado de la ropa al interior de Tacna (Perú), la venta de estos productos en las ferias de ropa y calzado usados y las diversas actividades económicas que circundan a las mencionadas ferias.

Nos resulta importante hacer mención de este proceso pues por más que la informalidad pueda afectar a determinados sectores vulnerables de la población, la propia informalidad presenta una marcada división de género en el trabajo. Esta es una característica clave en el caso de la venta de alimentos. 
Figura 6: Mujer vendedora de picante a la leña

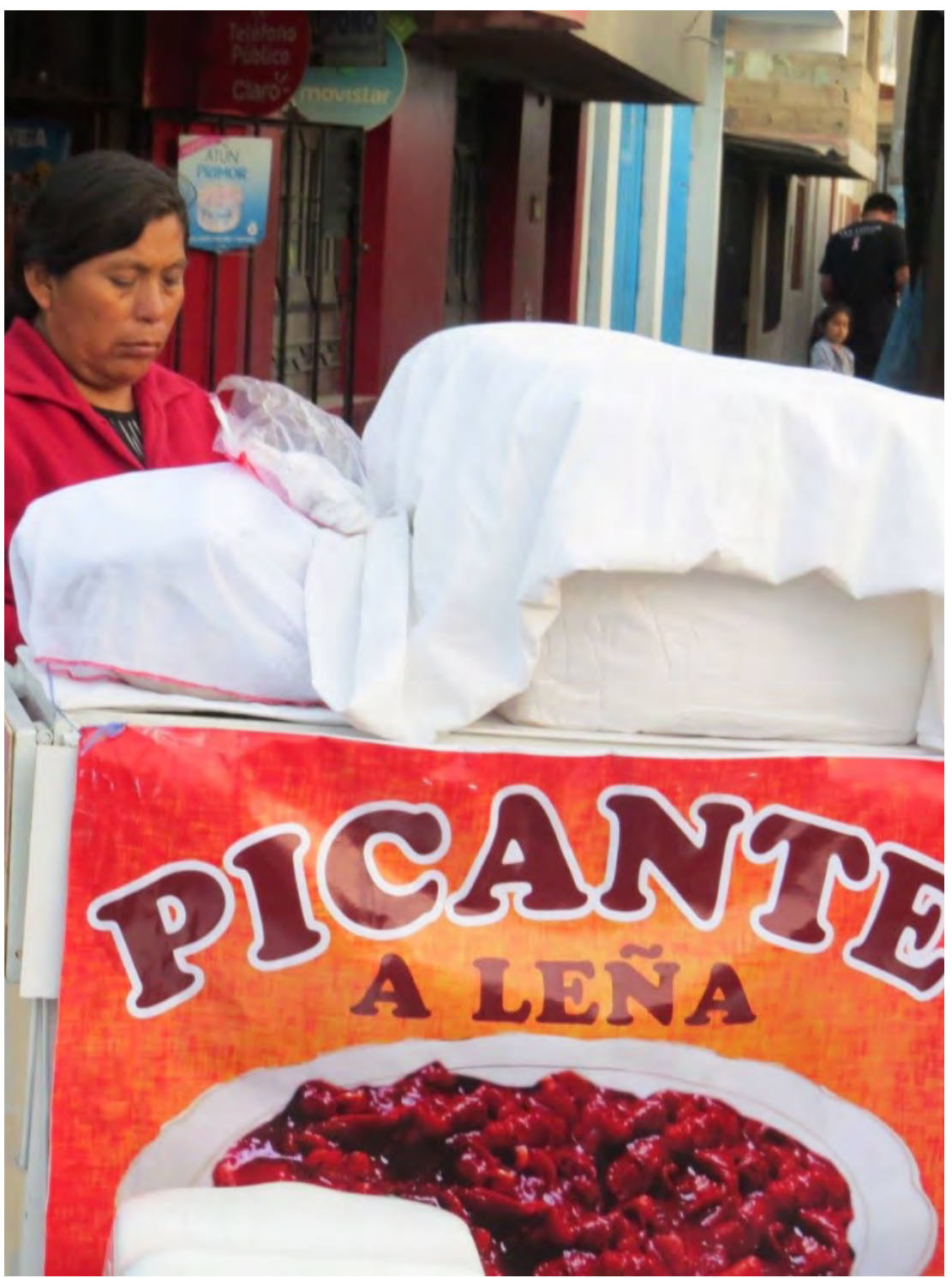

Fuente: Archivo personal.

Es sustancial hacer hincapié en la feminización de las prácticas informales ya que estas no solamente abarcan a la mayor parte de las comerciantes de ropa y calzado usados sino además producen dinámicas económicas y de supervivencia (Sassen, 2003) en los circuitos laborales anexos a la venta de ropa y calzado. Así, no solamente son principalmente las mujeres quienes venden ropa y calzado usados o quienes están insertas entre las comisionistas y las paseras (Dilla y Álvarez, 2018; Guizardi et al., 2014) sino además son las protagonistas en los comercios aledaños a las ferias con la venta de comida (Figura 6 y Figura 7). 
Figura 7: Mujer vendedora de alimentos

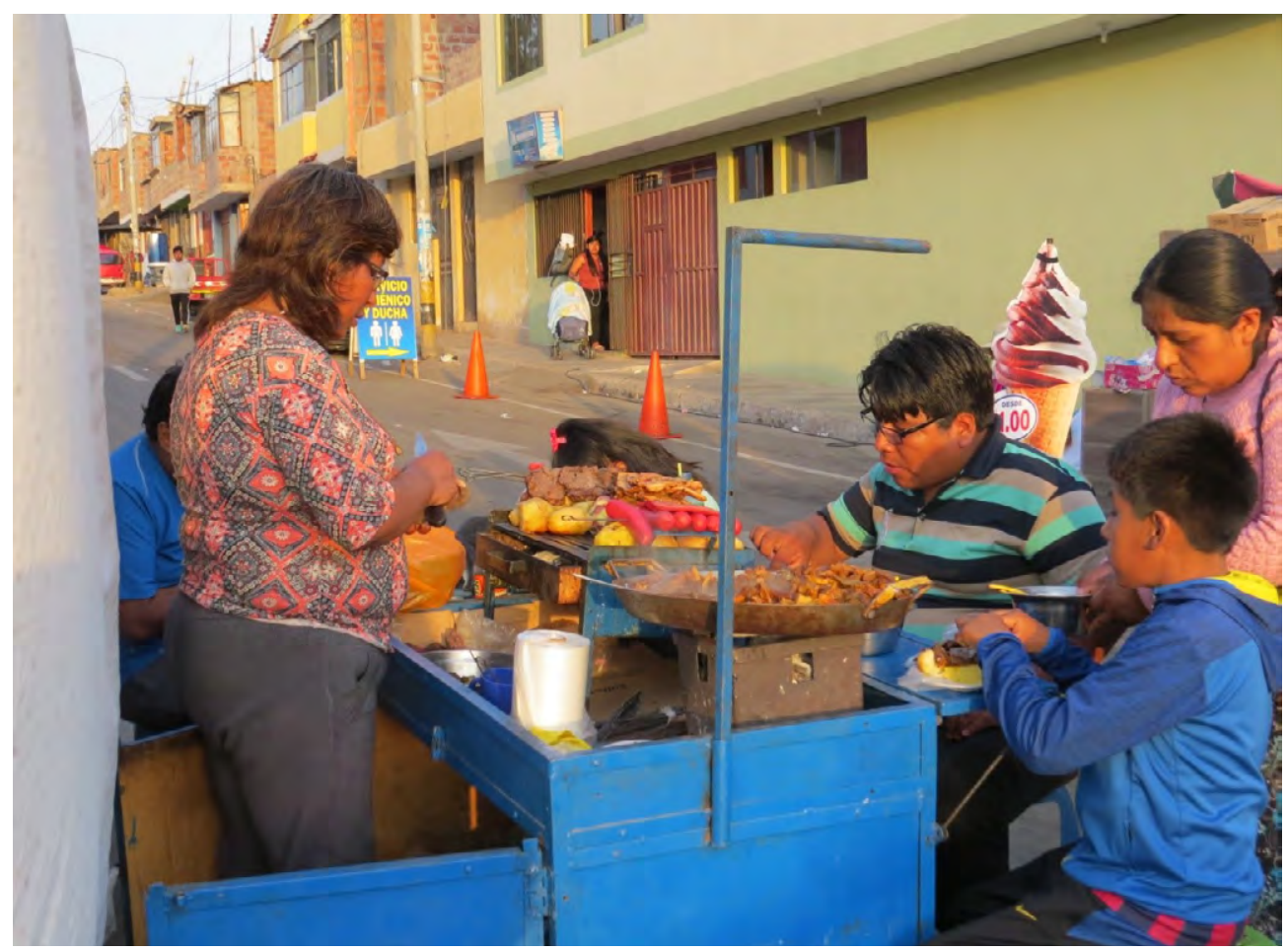

Fuente: Archivo personal.

El concepto de feminización de la supervivencia (Sassen, 2003) como clave analítica resulta importante en un contexto en el que los ingresos gubernamentales se obtienen a costa de los ingresos de las mujeres inscritas en las dinámicas de informalidad. Ello en tanto que la presencia del trabajo informal de la mujer permite un circuito de desarrollo del cual se benefician los gobiernos locales (bajo el pago de la tasa de impuesto dada al municipio), siendo que este trabajo informal se da en la venta y traslado de la ropa así como en la experiencia comercial construida a partir de la venta de los alimentos como uno de los principales comercios aledaños a las ferias.

Nuevamente, la profundización de las dinámicas sociales, económicas y culturales de las ferias de ropa y calzado usados nos permite reconsiderar una visión más amplia del corredor fronterizo peruano-chileno, más allá de lo tacno-ariqueño; ello al observar que las mismas características de la población sobreentendida como fronteriza (la presencia de las mujeres paseras) se extiende también en las ferias de ropa y calzado usados.

Finalmente, respecto de la inserción de los negocios, se observa que esto puede ser clasificado en quienes se ubican de forma semiestablecida en torno a los puestos de venta, y en quienes comercian recorriendo los pasajes de la feria. Los puestos semiestablecidos se ubican, mayormente de forma contigua, en carretillas dispuestas de bancas para el servicio de los comensales quienes a la sombra de una lona se acomodan para alimentarse. Los lugares donde están ubicados no suelen ser regulares, es decir, estos pueden ubicase al ingreso o a los extremos de las ferias debido a la facilidad en el ingreso de sus productos y herramientas de cocina, cerca de las avenidas que circundan la feria (Figura 8). 
Figura 8: Puestos semiestablecidos de comida

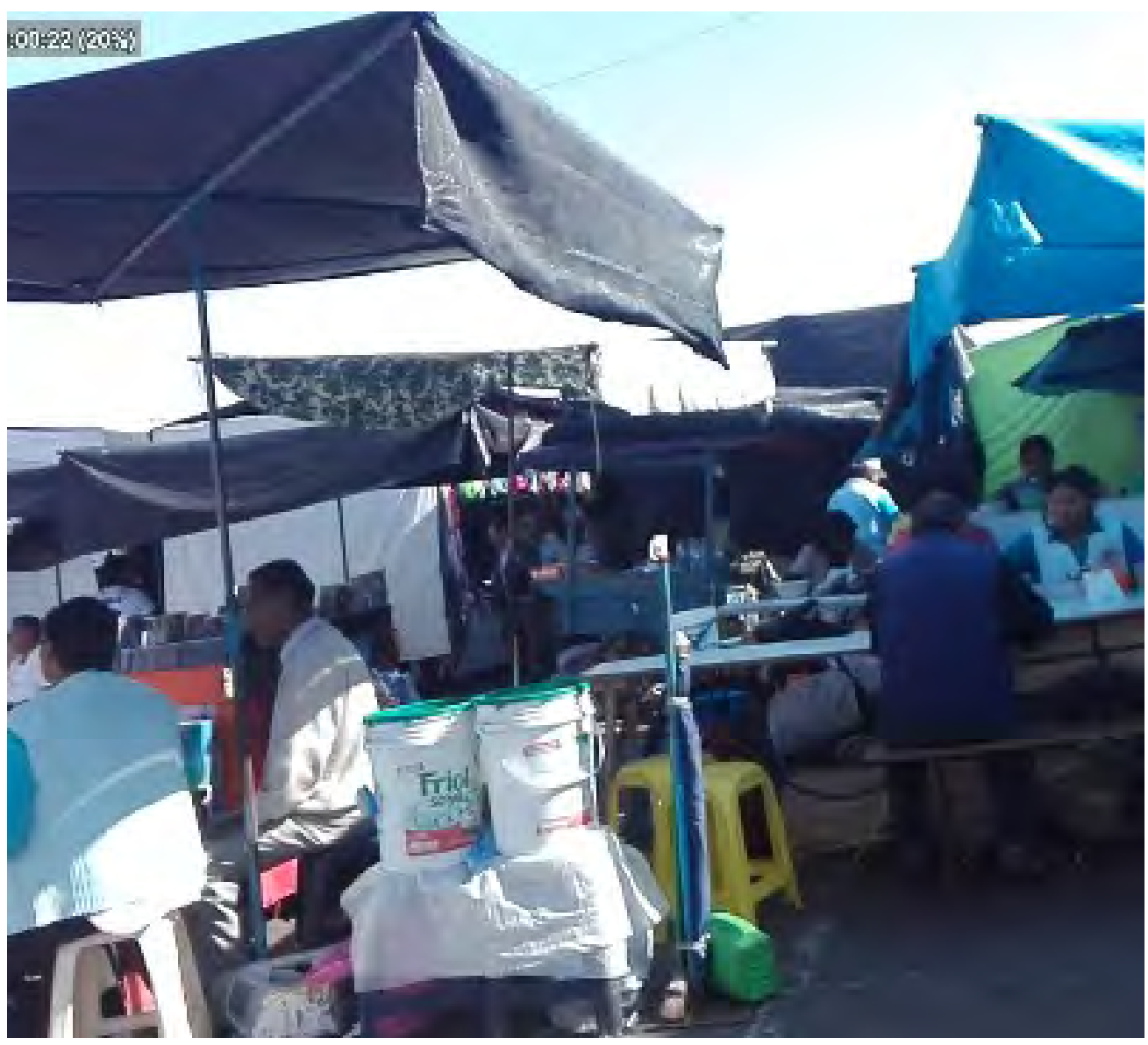

Fuente: Archivo personal.

Por otro lado, quienes optan por ofrecer sus productos al interior de la feria encuentran una diversidad de maneras de movilizarse entre las zonas más concurridas (Figura 9).

Para concluir esta parte, el comercio aledaño de alimentos en torno a los puestos establecidos de ropa y calzado de segundo uso nos permite una serie de claves analíticas de las dinámicas fronterizas peruano-chilenas. En primer lugar, la feminización de las actividades informales se extiende más allá de las esencializadas actividades de frontera como el comercio y el traslado de la ropa usada desde Chile hacia Perú. Esto último indica que las características del fenómeno fronterizo se extienden más allá de lo entendido propiamente como fronterizo, siendo que las actividades informales satélites a las ferias de ropa y calzado usado siguen guardando características similares.

A su vez, las actividades culinarias acompañan la experiencia del habitar en el comercio informal de frontera, debido a que la relación construida entre comerciantes y usuarios no se reduce únicamente a una relación comercial sino que construye una esfera pública de relaciones acompañada por las experiencias de la alimentación tanto entre los propios comerciantes como con los usuarios. 
Figura 9: Puestos móviles de comida

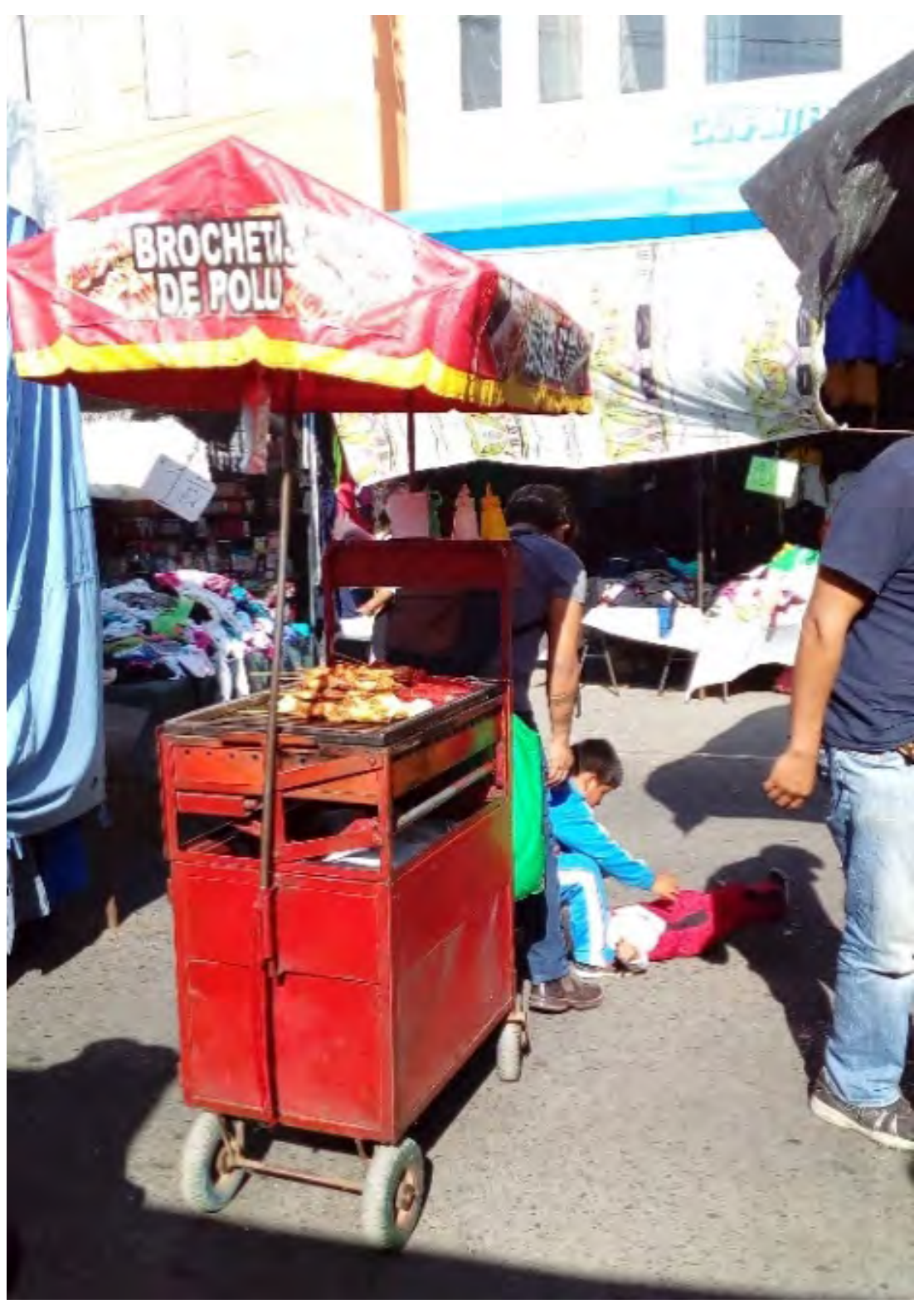

Fuente: Archivo personal.

Justamente, los detalles sobre la alimentación permiten reconstruir circuitos y corredores que trascienden el espacio tacno-ariqueño, pensado por antonomasia como el espacio fronterizo; siendo que este último se construye por medio de una serie de concatenaciones entre otros territorios como Puno, Ilave, Huancané, Chuchuito y Yunguyo, en el altiplano peruano, así como La Paz, Oruro, Desaguadero y Potosí en el territorio boliviano, extendiéndose a las mismas dinámicas creadas desde Iquique en Chile. De ahí que la presencia de alimentos de origen altiplánico nos permitan redibujar el corredor fronterizo más allá de lo que se ha entendido por esta frontera. 
Finalmente, la disposición de los puestos semiestablecidos así como el recorrido de los puestos móviles de comida reflejan una construcción del espacio comercial con base en la colaboración entre los puestos establecidos de comerciantes y los vendedores de comida; esta colaboración no se reduce únicamente a la disposición de los puestos sino que implica también la consolidación de lazos de confianza y reciprocidad reflejados en el cuidado del puesto de venta ante la ausencia del dueño, el sencilleo, el trueque y el fiado.

\section{Servicios de transporte}

El servicio de transporte en torno a las ferias presenta diversas manifestaciones. La presencia de la feria supone un aumento del flujo de la movilidad urbana y el transporte público en las áreas de venta, desde buses, taxis y mototaxis, ${ }^{13}$ al punto de que los dos últimos tipos de transporte presentan paraderos al interior de las ferias (Figura 10).

No obstante, la oferta de servicio de transporte no está dedicada únicamente a movilizar a los usuarios y clientes de la feria de ropa y calzado de segundo uso, cuyas rutas pueden ser muy heterogéneas e inciden en la propuesta analítica de la feria como articulador de corredores o nodo de ramificaciones de movilidad, más allá de lo netamente fronterizo.

Así, no solamente se transportan clientes sino ante todo los propios comerciantes y su mercadería, la cual sortea también, al interior de la ciudad, el constante control de los agentes de seguridad local. Además, el transporte de mercaderías ya ingresadas a la ciudad de Tacna desde Arica e Iquique (Chile) implica dos tipos: uno desde la vivienda de cada comerciante hacia la respectiva feria, y otro desde las afueras de la feria hasta el puesto de venta.

El transporte de la mercadería desde la vivienda hacia las ferias se hace con taxis Station Wagon, los cuales, en más de una ocasión, son conducidos por los propios comerciantes, tomando en cuenta la administración familiar del comercio, así como la complementación de otras actividades laborales como el transporte o el trabajo fronterizo. Por otro lado, el trasporte de la mercadería desde las afueras de la feria hasta el respectivo puesto de venta se hace por medio de carretillas conducidas principalmente por adultos mayores, quienes por un precio de 80 centavos de dólar trasladan las variadas mercaderías, como juguetes, ropa y calzado, entre otros (Figura 11).

\footnotetext{
${ }^{13}$ Motocicleta de tres ruedas y con techo que se usa como medio de transporte popular para trechos cortos (Real Academia Española, 2010).
} 


\section{Figura 10: Paradero de taxis}

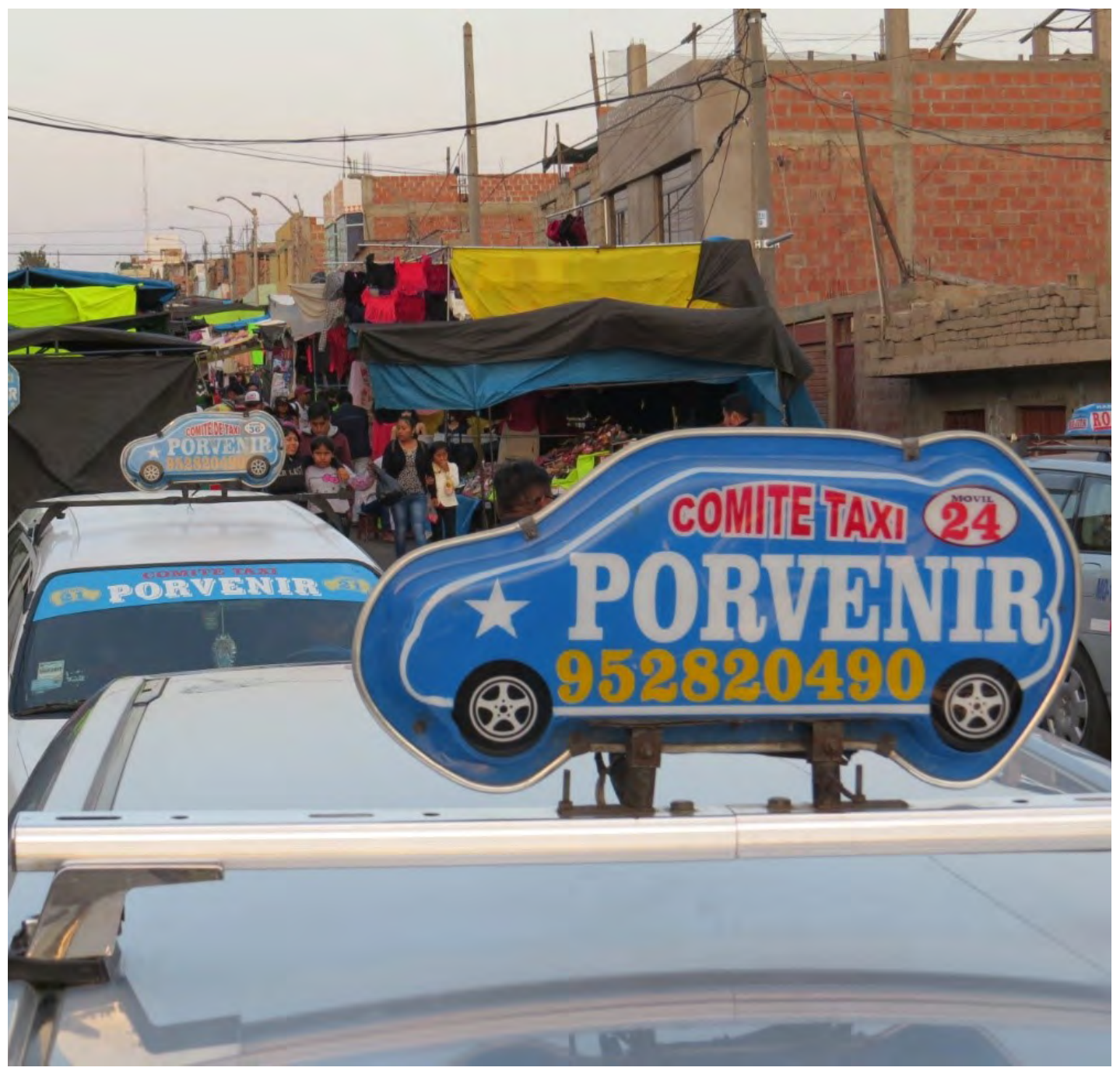

Fuente: Archivo personal.

El traslado de las mercaderías, tanto de forma interna como en los alrededores de la ciudad, se hace desde tempranas horas de la mañana (4 de la madrugada), retornándose a las últimas horas de la tarde ( 5 o 6 de la tarde). Esta actividad presenta un perfil determinado: el varón adulto y adulto mayor. A diferencia de la venta de alimentos, predominantemente femenina, el servicio de transporte cuenta con una preponderancia de varones adultos que pueden tener acceso a cierto capital para sostener el negocio de la movilidad. Sin embargo, la población masculina adulta mayor es el perfil de quienes transportan mercaderías en carretillas. Si bien no podemos hablar de la feminización de la supervivencia, sí podemos hacer hincapié en que las dinámicas de supervivencia económica al capitalismo se construyen sobre la base de la población subalterna y más desfavorecida. 


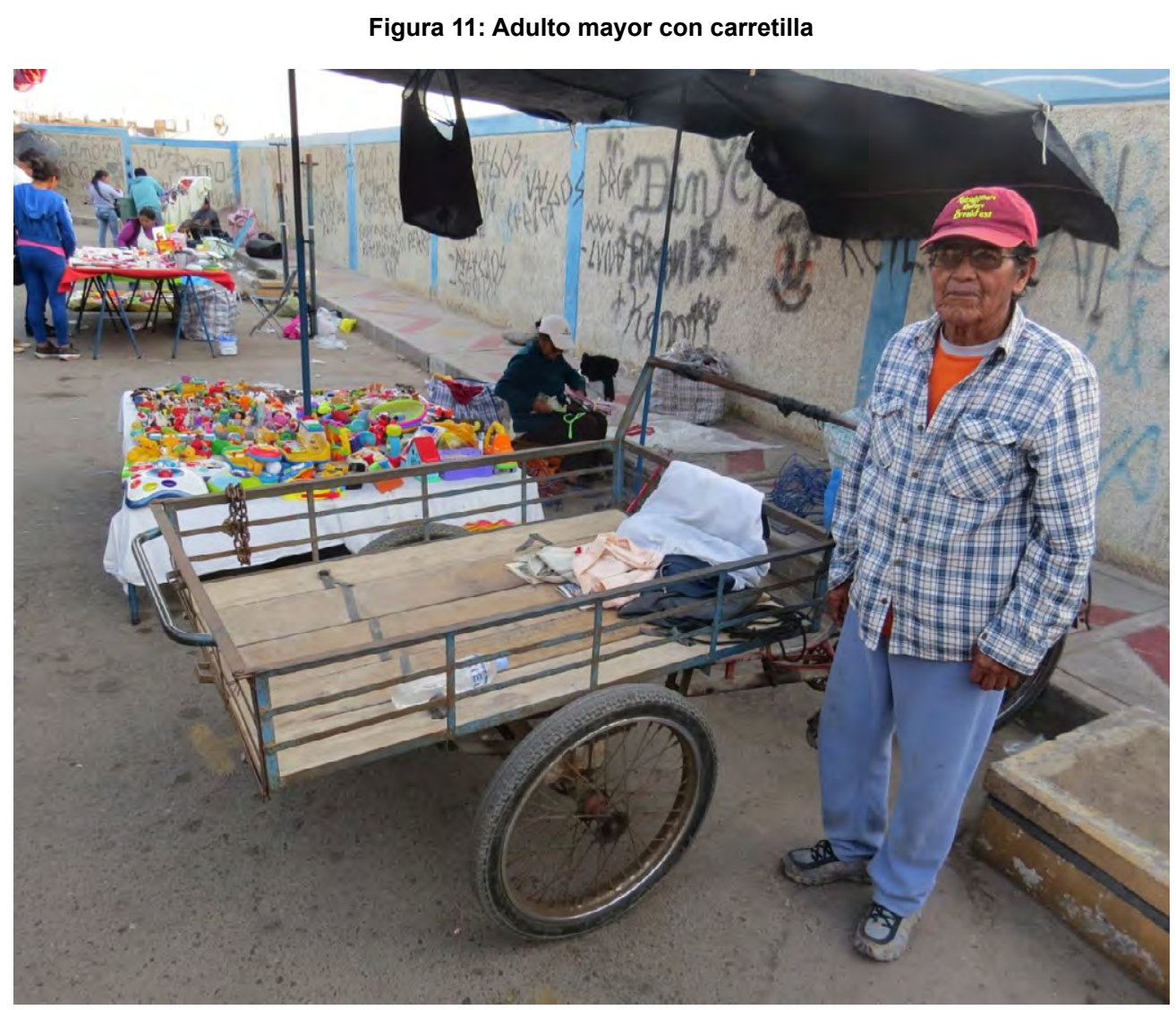

Fuente: Archivo personal.

Finalmente, como mencionamos en párrafos anteriores, el servicio de transporte en taxi y mototaxi ubica sus principales paraderos a los alrededores de las ferias, mientras que el grueso del transporte público moviliza a usuarios provenientes de distritos aledaños a Tacna como Ciudad Nueva, Gregorio Albarracín o Alto de la Alianza. Nuevamente, el acercamiento del fenómeno de la movilidad en torno a las ferias de ropa y calzado discute con el mentado isomorfismo del tacno-ariqueño del corredor fronterizo peruano-chileno, en tanto que se evidencian los diversos orígenes de los usuarios de las ferias más allá de la ciudad de Tacna.

\section{Otro tipo de servicios}

Por último, una sección conformada por otro tipo de servicios está constituida por venta de música, alquiler de baños, duchas y almacenes, así como la oferta de otros servicios principalmente de cuidado; además de ello, es posible encontrar servicios formales que ofertan telefonía móvil así como microfinancieras que brindan sus servicios a los comerciantes (Figura 12). 
Figura 12: Ofertando telefonía móvil

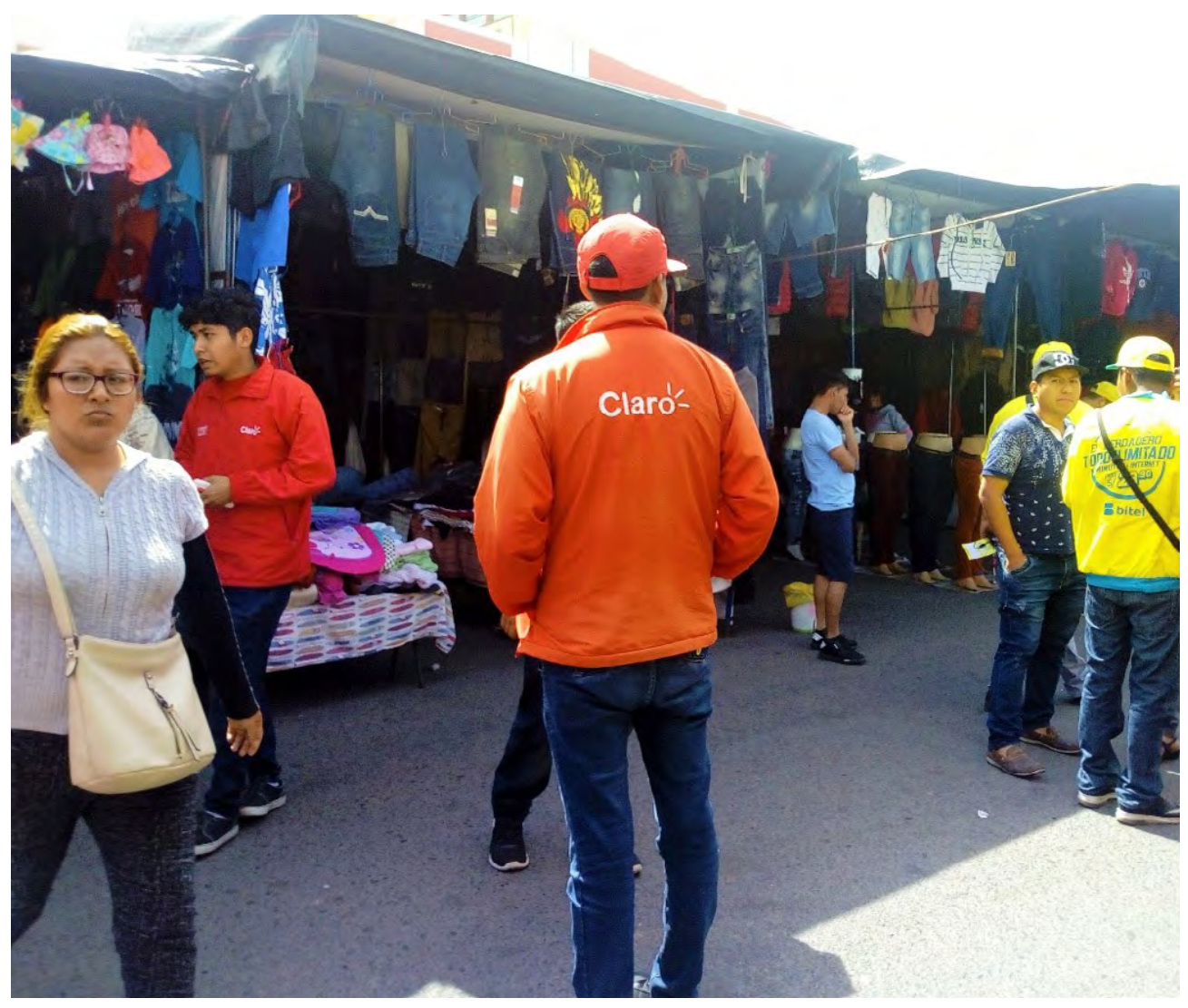

Fuente: Archivo personal.

El rubro otros servicios concentra negocios predominantemente informales como el alquiler de espacios en las viviendas aledañas a la feria, el alquiler de servicios de duchas y baños, además de la oferta de servicios de salud alternativa, que va desde masajes musculares y productos naturales para el cuidado de la piel, hasta tratamientos alternativos de malestares o enfermedades. Por otro lado, sectores formales de telefonía móvil o microfinancieras aprovechan la informalidad en dos sentidos amplios: el primero de ellos por las posibilidades que ofrece la feria en cuanto a la concurrencia y variedad del público comprador; en segundo lugar respecto de la oferta de trabajo en donde jóvenes, predominantemente subcontratados, deben alcanzar determinadas metas de venta de productos para sus salarios mensuales (Figura 13). 
Figura 13: Servicios de cuidado

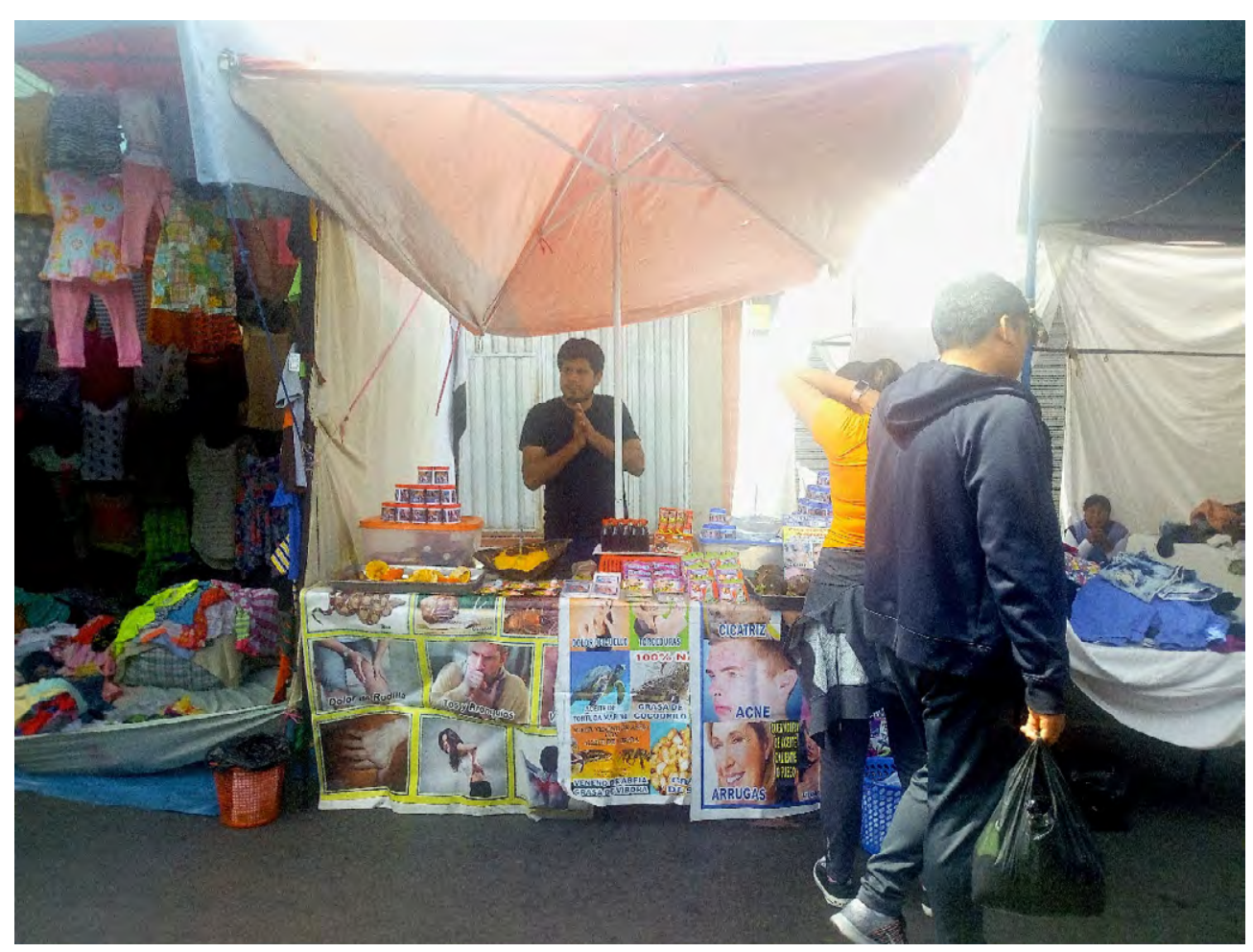

Fuente: Archivo personal.

Si bien el perfil de quienes ofrecen otros servicios es más heterogéneo de quienes ofrecen alimentos y transporte público, se observa una predominancia de trabajadores jóvenes, quienes, de diversa manera, reinventan formas de supervivencia económica gracias a las posibilidades que ofrecen las ferias de ropa y calzado de segundo uso.

De la misma manera que en la venta de comida, los puestos de otros servicios se ubican de forma itinerante al interior de la feria, principalmente los ambulantes que ofrecen servicio de cuidado, tales como limpieza o salud; mientras que otro tipo de servicios de puesto semiestablecido se ubica en las entradas y salidas de la feria, tales como la venta de música, financieras y telefonía móvil; mientras que la oferta de servicios de higiene, baños, duchas y almacenes se ubica principalmente en los extremos de la feria, en casas y hoteles aledaños a la feria.

Hasta esta parte, podemos notar que los comercios semiestablecidos alrededor de los puestos de la feria pueden ser tanto itinerantes como fijos. Ello denota una explicación en referencia a que sus principales usuarios no son únicamente los visitantes de la feria sino también los propios comerciantes, quienes necesitan de determinados servicios al pasar gran parte del día en la feria y al estar acompañados de la familia.

La situación de los usuarios tanto visitantes como comerciantes determina los diversos usos de estos servicios, desde la alimentación, el transporte y otros. Es importante hacer esta anotación ya que la presencia de servicios aledaños a los puestos establecidos en la ferias de ropa implica la construcción de una experiencia del habitar 
comercial dado al interior de las ferias. Los comerciantes y vendedores ambulantes no solamente mantienen una relación comercial sino además que el espacio comercial se constituye en un encuentro de interacción social entre compradores y comerciantes, así como entre comerciantes y vendedores de los negocios aledaños; el tipo de relación no transcurre únicamente en el cambio comercial (y en el posible rédito económico que esto signifique) sino implica además una interacción (Lacarrieu, 2016) que puede ir desde el préstamo de dinero y el cambio de sencillo hasta el cuidado de los puestos y la mercadería, entre otros.

Así, la heterogeneidad de los actores ubicados dentro y fuera de la feria de ropa y calzado de segundo uso, implica no solamente una interacción comercial sino también otros significados; en palabras de Ángela Giglia (2012), "la venta en la calle es una actividad atractiva - entre otras cosas- por la posibilidad que implica de estar en el espacio público abierto, ver pasar mucha gente y platicar y entablar relaciones con diferentes personas" (Giglia, 2012, p. 93). La consolidación de una esfera pública desde la relación social y comercial de compradores y venderos, se extiende por medio de la interacción entre los propios vendedores ya sea con el cuidado del puesto, los préstamos, los trueques y el sencilleo, ${ }^{14}$ así como con el cuidado del cuerpo de uno mismo o de los familiares. De ahí que la esfera pública construida por la heterogeneidad de los actores en las ferias de ropa y calzado de segundo uso, nos permite profundizar en la composición del corredor fronterizo peruano-chileno.

\section{Conclusiones}

Hasta aquí podemos advertir que la esfera pública producida en torno a la feria de ropa y calzado de segundo uso evidencia un comportamiento territorial más amplio que las categorías tacno-ariqueñas o chileno-peruanas, insertándose al Altiplano peruano y boliviano en esta relación. Más allá de un ámbito local, la frontera peruanochilena se produce a partir de una serie de concatenaciones de corredores menores ya sea desde Arica e Iquique en Chile, Desaguadero, La Paz, Oruro y Potosí en Bolivia, hasta Puno, Ilave, Huancané, Chuchuito, Yunguyo, Ciudad Nueva, Alto de la Alianza, Gregorio Albarracín y otras ciudades aledañas en el sur de Perú. Aquí abordamos una serie de indicios que nos llevan a considerar la importancia de estas evidencias a fin de profundizar el carácter complejo del territorio transfronterizo.

Una de las principales observaciones supone reducir el traspaso de ropa usada de Arica hacia Tacna como una actividad fronteriza exclusiva del corredor fronterizo peruano-chileno. Cuando en realidad es una actividad más compleja que concatena diversas ciudades y actores debatiendo la propuesta del corredor local e isomorfismo fronterizo tacno-ariqueño. Al observar que la actividad no se agota en Tacna y Arica, damos cuenta de que requerimos nuevas metodologías y enfoques estrictamente transfronterizos que nos permitan una adecuada interpretación de estos fenómenos.

La venta de ropa y calzado de segundo uso es una actividad que tiene como núcleo a los comerciantes de estos productos en las ferias itinerantes en el casco urbano de Tacna. Ellos compran los productos en Arica, los cuales a su vez son transportados

\footnotetext{
${ }_{14}$ De sencillar: "convertir billetes o monedas grandes en dinero menudo equivalente" (Real Academia
} Española, 2010). 
desde Iquique, ambas en Chile. Las mercancías adquiridas por los comerciantes peruanos pasan la frontera de Perú hacia Chile por medio de una estructura organizativa constituida por comisionistas y paseras, muchas veces sostenidas en estructuras familiares.

Sin embargo, la actividad no termina ahí. Una vez que las mercancías ingresan al territorio peruano, se pasa otro periplo, compuesto también por decomisos y detenciones, desde el paso fronterizo peruano hacia las viviendas de los comerciantes. Finalmente, estas mercancías son ofrecidas en las ferias de ropa y calzado de segundo uso, las cuales permiten la creación de dinámicas sociales, urbanas y económicas a nivel de Tacna, creando otras economías de subsistencia descritas en este artículo.

La profundización en las dinámicas de las ferias de ropa y calzado de segundo uso nos llevan a replantear la idea de la pasera como una de las figuras sine qua non del corredor fronterizo peruano chileno, y sus consecuencias, como acotar este corredor a la relación tacno-ariqueña a escala local. Las prácticas observadas en las ferias, así como las características de los actores nos llevan a considerar que el llamado corredor tacno-ariqueño es aún más complejo involucrando al corredor peruano-boliviano así como a ciudades y centros poblados aledaños a la región del altiplano.

\section{Referencias}

Alegría, T. (2009). Metrópolis transfronteriza. Revisión de la hipótesis y evidencias de Tijuana, México y San Diego, Estados Unidos. Tijuana: El Colegio de la Frontera Norte; Miguel Ángel Porrúa.

Altamirano, T. (s.f.). Los peruanos en el exterior y su revinculación con el Perú. Academia Diplomática. Recuperado de http://www4.congreso.gob.pe/historico/cip/ materiales/imigra/Peruanos_exterior_revinculacion.pdf

Altamirano, T. (2009). Migraciones, remesas y desarrollo en tiempos de crisis. Lima, Perú: Pontificia Universidad Católica del Perú.

Alvites, L. (2011). Madres e hijos/as de locutorio. La búsqueda de una familia sin fronteras. Lima, Perú: Forum Solidaridad Perú.

Berganza, I. y Cerna, M. (2011). Dinámicas migratorias en la frontera Perú-Chile. Arica, Tacna e Iquique. Lima, Perú: Universidad Antonio Ruiz de Montoya.

Bustamante, J. (1989). Frontera México-Estados Unidos: reflexiones para un marco teórico. Frontera Norte, 1(1), 7-24.

Bustos, R. (2017). Expectativas académicas de estudiantes y padres migrantes: el caso de Arica, en la frontera de Chile y Perú. Revista Dilemas Contemporáneos: Educación, Política y Valores, (03), 01-28. Recuperado de https://dilemascontemporaneoseducacionpoliticayvalores.com

Cavieres, E. (2006). Chile-Perú, la historia y la escuela. Conflictos nacionales, percepciones sociales. Valparaíso, Chile: Pontificia Universidad Católica de Valparaíso.

Cavieres, E. (2015). Conversaciones en Lima. La historia como instrumento de integración chileno-peruana. Valparaíso, Chile: Pontificia Universidad Católica de Valparaíso. 
Cavieres, E. y Aljovín de Losada, C. (2005). Chile-Perú, Perú-Chile: 1820-1920. Desarrollos políticos, económicos y culturales. Valparaíso, Chile: Pontificia Universidad Católica de Valparaíso.

Dammert, M., Bensús, V., Sarmiento, K. y Prieto, G. (2017). Una aproximación a las fronteras desde los mercados ilegales en el Perú. Quito, Ecuador: Facultad Latinoamericana de Ciencias Sociales, Sede Ecuador.

Dilla, H. (2008). Las ciudades en la frontera: introducción a un debate. En H. Dilla (Coord.), Ciudades en la frontera: Aproximaciones críticas a los complejos urbanos transfronterizos (pp. 167-204). Cristo Rey, Santo Domingo: Editora Manatí.

Dilla, H. (2015). Los complejos urbanos transfronterizos en América Latina. Estudios Fronterizos, 16(31), 15-38. doi:https://doi.org/10.21670/ref.2015.31.a01

Dilla, H. y Álvarez, C. (2018). Economía e intercambio desigual en una región transfronteriza: Arica, Chile-Tacna, Perú. Estudios Fronterizos, 19, e009. doi: http:// doi.org/10.21670/ref.1809009

Giglia, A. (2012). El habitar y la cultura, perspectivas teóricas y de investigación. Ciudad de México, México: División de Ciencias Sociales y Humanidades, Universidad Autónoma Metropolitana-Iztapalapa.

Guizardi, M., Heredia, O., Muñoz, A., Riquelme, G. y Valdebenito, F. (2014). Experiencia migrante y apropiaciones espaciales: una etnografía visual de las inmediaciones del Terminal Internacional de Arica (Chile). Revista de Estudios Sociales, (48), 166-175. Doi: http://dx.doi.org/10.7440/res48.2014.13

Guizardi, M., Nazal, E., Valdebenito, F. y López, E. (2017). Sincerar los trucos. Una etnografía comparada sobre la migración femenina peruana en Arica, Iquique, Valparaíso y Santiago (Chile). Etnografías Contemporáneas, 3(05), 26-33.

Guizardi, M., Valdebenito, F., Nazal, E. y López, E. (2017). Hyper-Border Spaces: Peruvian Migrants in the Arica Bus Terminal (Chile). Migraciones Internacionales, 09(01), 151-178. Recuperado de http://www.scielo.org.mx/pdf/migra/ v9n1/1665-8906-migra-9-01-00151.pdf

Graña, F. (2001). Cambio casera: comercio y relaciones fronterizas en el extremo norte de Chile. Actas del $4^{\circ}$ Congreso Chileno de Antropología, Simposio Fronteras y Corredores. Recuperado el 18 de febrero de 2018 de http://www.aacademica.org/ iv.congreso.chileno.de.antropologia/172

Grimson, A. (2004). Fronteras, naciones y región. Ponencia, Foro Social de las Américas, Quito, Ecuador.

Hernández, A. y Loureiro, F. (2017). Ropas americanas: Comercio, contrabando y compradores de ropa usada en la frontera de Corumbá, Brasil, y Puerto Quijarro, Bolivia. Frontera Norte, 29(57). Recuperado de http://fronteranorte.colef.mx

Hernández, R., Fernández, C. y Baptista, M. (2010). Metodología de la investigación. Ciudad de México, México: McGraw-Hill.

Herzog, L. (1990). Border Commuter Workers and Transfrontier Metropolitan Structure along the United States-Mexico Border. Journal of Borderlands Studies, 5(2), 1-20. doi 10.1080/08865655.1990.9695393

Jiménez, R. (2018). Criminalización de la economía informal en las fronteras sudamericanas. Estudio de caso de la Triple Frontera del Paraná y la Triple Frontera Central Sur Andina (Tesis de maestría). Universidade Federal da Integração Latino-Americana, Brasil. Recuperado de https://dspace.unila.edu.br 
Jiménez, R. (2019). Comercio informal en ciudades de frontera. Estudio de caso de los feriantes de ropa y calzado en la ciudad de Tacna (Perú). Si Somos Americanos, 19(01), 13-42. doi: http://dx.doi.org/10.4067/S0719-09482019000100013

Lacarrieu, M. (2016). "Mercados Tradicionales" en los procesos de gentrificación/ recualificación. Consensos, disputas y conflictos. Alteridades, 26(51), 29-41. Recuperado de https://www.redalyc.org/pdf/747/74747921003.pdf

Liberona, N., Tapia, M. y Contreras, Y. (2017). Movilidad por salud entre Arica y Tacna: Análisis de una demanda no satisfecha y de una oferta atractiva del otro lado de la frontera. Geopolítica(s). Revista de Estudios sobre Espacio y Poder, 8(02). Recuperado de http://revistas.ucm.es

Massó, E. (2013). Superando el nacionalismo metodológico: comunidades cosmopolitas de interacción en el barrio de Lavapiés. Migraciones Internacionales, 7(2), 71-100. Recuperado de http://www.scielo.org.mx/scielo.php?script=sci_arttext\&pid=S1665-89062013000200003

Ministerio de Relaciones Exteriores de Perú, MRE. (2015). Delimitación marítima entre el Perú y Chile ante la Corte Internacional de Justicia. Tomo Iv: El Fallo de la Corte Internacional de Justicia. Lima, Perú: Fondo Editorial del Congreso del Perú.

Panfichi, A. y Venero, E. (2017). La frontera disputada. La ruta a la sentencia de La Haya. Lima, Perú: Pontificia Universidad Católica del Perú.

Parodi, D. y González, S. (2014). Las historias que nos unen. 21 relatos para la integración entre Perú y Chile. Lima, Perú: Pontificia Universidad Católica del Perú.

Pastor, M. (2017). Construcciones y persistencias identitarias en Tacna (1940-2017). La tensión entre tacneños y puneños por su afirmación cultural en la ciudad (Tesis de maestría). Universidade Federal da Integração Latino-Americana, Foz de Iguaçu, Paraná, Brasil. Recuperado de https://dspace.unila.edu.br/bitstream/handle/123456789/3552/MARLY_PASTOR_DISERTACION\%2bFICHA CATALOGRÁFICA-UNILA.pdf?sequence $=1$ \&isAllowed $=y$

Pérez, A. (2013). Ropa usada: hechura de culturas. En M. Olmos (Coord.), Antropología de las fronteras. Alteridad, historia e identidade más allá de las líneas [versión Adobe Digital Editions].

Pérez, C. (20 de abril de 2011). El api: la bebida típica de Bolivia. Diario del Viajero. Recuperado de https://www.diariodelviajero.com/america/el-api-la-bebida-tipica-de-bolivia

Pizarro, E. y Bustos, R. (2015). Educación y control político-social del Estado. Visitadores de Escuela en Tacna y Arica (1880-1900). Revista Historia de la Educación Latinoamericana, 17(25), 125-138. Recuperado de http://www.redalyc.org/articulo.oa?id $=86941142008$

Ponce, B. (2017). Entre o estigma e o reconhecimento: práticas culturais de aimarás na cidade de Tacna-Perú (Tesis de maestría). Universidade de Brasília, Brasília, Brasil.

Ponce, B. (2018). Trayectorias de inserción urbana de aymarás en Tacna: la construcción del distrito de Ciudad Nueva. Arquitek, 13, 18-27. Recuperado de http:// revistas.upt.edu.pe/ojs/index.php/arquitek/article/view/26/21

Real Academia Española. (2005). Diccionario de la Lengua Española. Madrid, España: Real Academia Española. 
Real Academia Española. (2010). Diccionario de Americanismos. RAE.

Sassen, S. (2003). Contrageografías de la globalización. Género y ciudadanía en los circuitos transfronterizos. Madrid, España: Traficante de Sueños. Recuperado de http://www.acuedi.org/ ddata/9217.pdf

Tapia, M. (2012). Frontera y migración en el norte de Chile a partir del análisis de los censos de población. Siglos xix-xxi. Revista de Geografía Norte Grande, (53), 177198. Recuperado de https://scielo.conicyt.cl/scielo.php?script=sci_arttext\&pi$\mathrm{d}=\mathrm{S} 0718-34022012000300011$

Tapia, M. (2017). Las fronteras, la movilidad y lo transfronterizo: Reflexiones para un debate. Estudios Fronterizos, 18(37), 61-80. doi:https://dx.doi.org/10.21670/ref.2017.37.a04

Tapia, M., Liberona, N. y Contreras, Y. (2017). El surgimiento de un territorio circulatorio en la frontera chileno-peruana: Estudio de las prácticas socio-espaciales fronterizas. Revista de Geografía Norte Grande, (66), 117-141. Recuperado de http://scielo.conicyt.cl

Valdebenito, F. (2018). Capitalismo, espacio y geografía en la frontera peruano-chilena contemporánea (segunda década del siglo XXI): hacia una escala de la urbanización fronteriza tacno-ariqueña. Revista Chilena de Antropología, (37), 287-309. doi:10.5354/07191472.2018.49517

Valdebenito, F. y Guizardi, M. (2015). Espacialidades migrantes. Una etnografía de la experiencia de mujeres peruanas en Arica (Chile). Gazeta de Antropología, 31 (01). Recuperado de http://dialnet.unirioja.es

Ricardo Jiménez Palacios

Peruano. Filósofo por la Universidad Nacional Mayor de San Marcos (Perú) y maestro en integración contemporánea de América Latina por la Universidade Federal da Integração Latino-Americana (Brasil). Actualmente labora como docente e investigador en la Universidad Privada de Tacna (Perú). Líneas de investigación: estudios fronterizos, geopolítica crítica y violencia. Publicación reciente: Jiménez, R. (2018). Genealogía de las fronteras y el territorio en el Perú. Un análisis constitucional. Desde el Sur, 10(2), 377-391.

Priscilla Francesca Bachmann Benites

Peruana. Estudiante de la Facultad de Arquitectura y Urbanismo en la Universidad Privada de Tacna. Recientemente ha publicado un artículo en el congreso "El potencial transfronterizo de las prácticas socio-territoriales: Estudio del impacto de la movilidad humana chilena en el entorno urbano tacneño, como ciudad intermedia" (2018), en el Seminario Internacional Ciudades intermedias y desigualdades territoriales en el Perú y "La producción social del hábitat en la zona fronteriza de Tacna y Arica" (2017) en el III Encuentro Nacional de Investigación en Arquitectura y Urbanismo: Experiencias, Logros y Desafíos.

Nicole Loza Delgado

Peruana. Estudiante de la Facultad de Arquitectura y Urbanismo en la Universidad Privada de Tacna. Recientemente ha publicado un artículo en el congreso "El potencial transfronterizo de las prácticas socio-territoriales: Estudio del impacto de la movilidad humana chilena en el entorno urbano tacneño, como ciudad intermedia" (2018), en el Seminario Internacional Ciudades intermedias y desigualdades territoriales en el Perú. 